\title{
Comparative Analysis of Downlink Packet SCHEDULING ALGORITHMS IN 3GPP LTE NETWORKS
}

\author{
Farhana Afroz ${ }^{1}$, Roshanak Heidery ${ }^{2}$, Maruf Shehab ${ }^{3}$, Kumbesan Sandrasegaran ${ }^{4}$ \\ and Sharmin Sultana Shompa ${ }^{5}$ \\ ${ }^{1,2,4}$ Faculty of Engineering and Information Technology, \\ University of Technology, Sydney, Australia \\ ${ }^{3}$ Independent Researcher, UK \\ ${ }^{5}$ Department of Electronic and Communication Engineering, BIST, Bangladesh
}

\begin{abstract}
Long Term Evolution (LTE) mobile network aims to support high speed network services even in highmobility scenarios. To achieve this goal, LTE adopts some advanced features in Radio Resource Management (RRM) procedures. Among them, LTE packet scheduling plays a fundamental role in maximising system performance. In this paper, a comparative analysis on the performances of Proportional Fair (PF), Exponential/Proportional Fair (EXP/PF), Exponential (EXP) Rule, MaximumLargest Weighted Delay First (M-LWDF), Logarithmic (LOG) Rule and Frame Level Scheduler (FLS) LTE downlink packet scheduling algorithms is reported. Performance is evaluated in single cell with interference environment while increasing user number and user speed. Results show that for multimedia flow, FLS scheme outperforms other five schemes in terms of packet delay, packet loss ratio, and average throughput, whereas for best-effort flow, EXP-PF scheme shows better average throughput performance on average as compared with other algorithms being considered herein.
\end{abstract}

\section{KEYWORDS}

LTE, RRM, Packet Scheduling Algorithm, QoS, Performance Metrics

\section{INTRODUCTION}

The growing demands of ubiquitous broadband services, such as real-time gaming, social networking, conversational video, location-based services, live streaming and so on, together with the storage and data processing capabilities of end terminals, such as tablets, smartphones, are causing the exponential upsurge of mobile data traffic in recent years $[1,2]$. Long Term Evolution (LTE) mobile network, standardized by 3GPP (Third-Generation Partnership Project), aims to fulfil these demands by providing high spectral efficiency, high peak data rates, low userplane latency, improved coverage and capacity, low operating cost, enhanced support of end-toend QoS (Quality of Service), and spectrum flexibility [3]. To attain these targets, LTE exploits new packet-optimized system architecture as well as some physical layer technologies such as Orthogonal Frequency Division Multiple Access (OFDMA) in downlink, Single Carrier Frequency Division Multiple Access (SC-FDMA) in uplink and multiple antenna techniques [4, 5]. OFDMA radio access technology is chosen instead of WCDMA (Wideband Code Division Multiple Access) employed in UMTS (Universal Mobile Telecommunications System) as

DOI : 10.5121/ijwmn.2015.7501 
International Journal of Wireless \& Mobile Networks (IJWMN) Vol. 7, No. 5, October 2015

OFDMA provides higher spectral efficiency, delivers good performance in frequency selective fading channels, mitigates inter-symbol interference because of its orthogonal characteristics, improves network capacity, supports low-complexity receivers, and is compatible with some advanced features (e.g. frequency domain scheduling, multiple antenna technologies). LTE system, also termed as Evolved packet system (EPS), is based on a flat architecture with less involved nodes that reduces latencies and improves system performance [6]. LTE architecture consists of two main parts such as Evolved Universal Terrestrial Radio Access Network (EUTRAN), and Evolved Packet Core network (EPC). E-UTRAN comprises of eNodeBs only where all radio interface-related functions such as physical layer functions, scheduling, ciphering, header compression and encryption of the user data stream, MME (Mobility Management Entity) selection, admission control, radio bearer control, and inter-cell RRM are performed [3]. In packet scheduling, the available air-interface resources are efficiently allocated among active UEs so as the QoS requirements of the UEs are satisfied [7, 8]. Packet scheduling plays a vital role to enhance system performance, and aims to maximise cell capacity, satisfy the minimum QoS requirements for the users, and maintain adequate radio resources for best-effort users with no strict QoS requirements [6]. A range of resource allocation strategies has been proposed for LTE networks since there is no 3GPP-specified LTE scheduling algorithm. It is an open issue for the vendors to implement an algorithm. This paper provides a comparative study of the performances of six packet scheduling algorithms while increasing the number of users and users' speed in single-cell with interference environment.

The rest of this paper is organised as follows. Section 2 provides the overall description of a generalized packet scheduling model in LTE downlink. Section 3 outlines the scheduling schemes being considered in this paper to analyse their performance followed by illustrations of the simulation scenarios and results in Section 4. Finally, the paper is concluded with Section 5.

\section{Packet Scheduling in LTE Downlink}

In LTE, OFDMA radio access technology is chosen for downlink data transmission in which the available system bandwidth is split into parallel narrow-band orthogonal sub-carriers with subcarrier spacing of $15 \mathrm{kHz}$ irrespective of total bandwidth [3, 8]. Radio resources are defined in time-frequency domain (shown in Fig. 1). In the time domain, time is divided into frames, and each LTE frame consists of 10 consecutive subframes or TTIs (Transmission Time Interval) each of which is of $1 \mathrm{~ms}$ in duration i.e. each LTE radio frame is $10 \mathrm{~ms}$ in duration. Each subframe is made of two time slots where each slot is of $0.5 \mathrm{~ms}$ duration. There are 7 OFDM symbols (with short cyclic prefix) in each time slot. In the frequency domain, the total available system bandwidth is divided into sub-channels. Each LTE sub-channel corresponds to 12 successive and equally-spaced sub-carriers with sub-carrier spacing of $15 \mathrm{kHz}$ i.e. each sub-channel is of 180 $\mathrm{kHz}(12 \times 15 \mathrm{kHz})$ width. A time-frequency radio resource spanning over one sub-channel of 12 sub-carriers in the frequency domain and one time slot of $0.5 \mathrm{~ms}$ in the time domain is known as Resource Block (RB). The smallest unit of RB which corresponds to one OFDM subcarrier during one symbol interval is called Resource Element (RE) [9]. In packet scheduling, resources are allocated in pairs which is known as Physical Resource Block (PRB). PRB can be defined as the minimum amount of resources that can be assigned to a UE for data transmission on every TTI. 


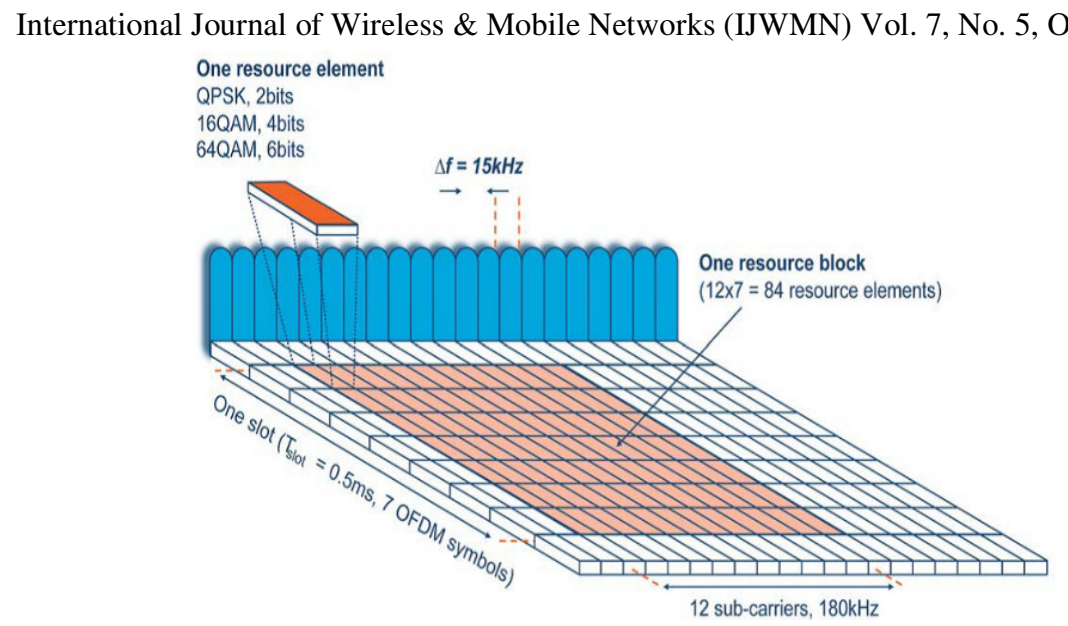

Figure 1: Resource Block structure

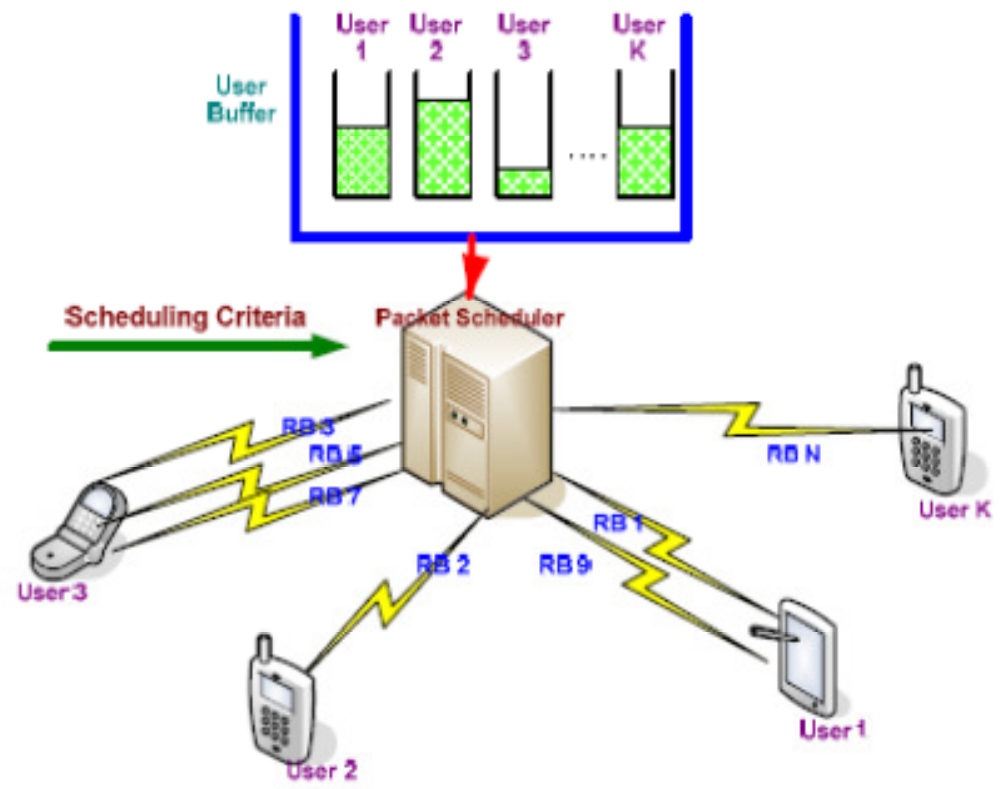

Figure 2: A generalized packet scheduling model in LTE downlink [10]

In LTE, packet scheduling is performed in eNodeB. A generalized packet scheduler in LTE downlink network is shown in Fig. 2. On every TTI, each user reports its CQI (Channel Quality Indicator) computed from its downlink instantaneous channel condition to the serving eNodeB. CQI, a quantized and scaled measure of SINR (Signal to Interference plus Noise Ratio), selects the most suitable Modulation and Coding Scheme (MCS) to maximise system throughput at that SINR. At eNodeB, there is a buffer assigned for each user. The incoming data packets are buffered, time-stamped and queued for transmission on first-in-first-out basis. On each TTI, resource allocation decision is made depending on packet scheduling strategies, and one or multiple PRBs can be allocated for each user. Various scheduling algorithms exhibit particular scheduling criteria (e.g. queue status, channel condition, head of line packet delay, traffic type etc.) based on which UEs are prioritized by the scheduler. A user with highest metric is chosen by the eNodeB to transmit its data. Once a user is scheduled based on scheduling algorithm, the number of transmitted bits per PRB depends on the selected MCS [10-13]. 
International Journal of Wireless \& Mobile Networks (IJWMN) Vol. 7, No. 5, October 2015

\section{Packet Scheduling Algorithms}

LTE packet scheduling schemes aim to maximise system performance. Performances of scheduling strategies are measured in terms of system metrics, such as throughput, packet loss ratio, packet delay, fairness index, and spectral efficiency. Real-time (RT) applications are delay sensitive and requires GBR (Guaranteed Bit Rate). In contrary, non-real time (NRT) services are less delay sensitive and require high throughput and low error rates. The packet scheduling algorithms being considered in this work are described as follows.

\subsection{Proportional Fair (PF)}

Proportional Fair, proposed in [14], is a channel-aware/QoS-unaware strategy that takes into account both the CQI and user's past average data rate while allocating resources to the user [15]. The goal of this algorithm was to maintain a trade-off between the fairness and network throughput [16]. It chooses an UE whose metric $M$ is highest. The priority metric, $M$ is given in the following equation.

and

$$
M=\operatorname{argmax} \frac{R_{i}(t)}{R_{l}(t)}
$$

$$
\bar{R}_{i}(t)=\left(1-\frac{1}{t_{c}}\right) * \bar{R}_{i}(t-1)+\frac{1}{t_{c}} * R_{i}(\mathrm{t}-1)
$$

where, $\mathrm{R}_{i}(t)$ is the instantaneous achievable transmission rate

$\bar{R}_{i}(t)$ is the average data rate of user $i$ at time $t$.

$t_{c}$ is the update window size

$\bar{R}_{i}(t-1)=0$ if user $i$ is not selected for transmission at time $t-1$

From Eq. 1, it can be realized that this packet scheduling scheme provides higher priority not only to the users with good CQI but also to the users with low average data rate [17].

\subsection{Maximum-Largest Weighted Delay First (M-LWDF)}

M-LWDF proposed in [18] supports multiple RT data users with different QoS requirements. It considers both the CQI as well as the queue status while making scheduling decision. Resource Blocks(s) is/are allocated to a user based on the following priority metric, $\mathrm{M}$.

and

$$
M=\operatorname{argmax} a_{i} W_{i}(t) \frac{R_{i}(t)}{\bar{R}_{i}(t)}
$$

$$
a_{i}=-\frac{\log \delta_{i}}{\tau_{i}}
$$

where $W_{i}(t)$ is the HOL (Head Of Line) packet delay of user $i$ at time $t$

$\tau_{\mathrm{i}}$ is the delay threshold of user $i$ and

$\square_{i}$ is the maximum probability of HOL packet delay of user $i$ to exceed the delay threshold of user $i$.

Here, HOL delay is defined as the time difference between the current time and the time at which the packet arrived. The implementation of this algorithm requires that the packet scheduler at eNodeB time stamps the incoming data packets and keeps track the states of current queue, particularly queue length [16]. 


\subsection{Exponential/Proportional Fair (EXP/PF)}

EXP/PF $[19,20]$ was proposed to support both RT services with different QoS requirements and NRT data services in an AMC/TDM (Adaptive Modulation and Coding and Time Division Multiplexing) system. It is a composite of EXP Rule and PF algorithm. PF properties ensure the maximization system throughput and EXP properties guarantee the delay constraints of RT services. The scheduling metric, $M$ is based on the service type (i.e. RT/NRT) of each user.

$$
M=\arg \max \left\{\begin{array}{lr}
\exp \left(\frac{a_{i} W_{i}(t)-a \overline{W(t)}}{1+\sqrt{a W(t)}}\right) \frac{R_{i}(t)}{\bar{R}_{i}(t)} & i \epsilon R T \\
\frac{w(t)}{P(t)} \frac{R_{i}(t)}{\bar{R}_{i}(t)} & i \in N R T
\end{array}\right.
$$

and, $\quad a \overline{w(t)}=\frac{1}{N_{R T}} \sum_{i \in R T} a_{i} W_{i}(t)$

$$
w(t)= \begin{cases}w(t-1)-\varepsilon & W_{\max }>\tau_{\max } \\ w(t-1)+\frac{\varepsilon}{k} & W_{\max }<\tau_{\max }\end{cases}
$$

where, $P(t)$ is the average number of RT packets waiting at the serving eNodeB buffer at time $t$ $\varepsilon$ and $k$ are constants

$W_{\max }$ is the maximum HOL packet delay out of all RT service users

$\tau_{\max }$ is the maximum delay constraint of all RT service users.

PF properties provide higher priority to the user with better CQI but the EXP rule provides higher priority to the user having more data packets in its buffer [16]. EXP/PF gives higher priority to the RT service users if their HOL packet delays approach delay deadline [21].

\subsection{Frame Level Scheduler (FLS)}

FLS algorithm, proposed in [22], is a QoS-aware scheduling algorithm that is designed for RT communications in LTE downlink networks. It is a two-level scheduling scheme in which two separate levels (highest level and lowest level) interact with each other to dynamically schedule resource blocks to UEs. At the highest layer, a less complex algorithm based on Discrete-Time (DT) linear control loop is implemented. This algorithm (namely FLS) specifies the amount of data packets that should be transmitted by each RT source in a single frame. At the lowest level, radio resources are assigned to the users on every TTI using PF strategy with taking into consideration the bandwidth requirements of FLS. The lowest level packet scheduler schedules RBs on every TTI to ensure a trade-off between system throughput and fairness. For FLS algorithm, the amount of data to be transmitted is calculated using following equation [7]:

$$
v_{i}(k)=h_{i}(k) * q_{i}(k)
$$

Where, $v_{i}(k)$ denotes the quota of data to be transmitted by the $i$-th flow in $k$-th LTE frame,

"*" is the DT convolution operator,

$q_{i}(k)$ is the queue level and

$h_{i}(k)$ is the pulse response.

Eq. (8) describes that $v_{i}(k)$ is obtained by filtering the signal $q_{i}(k)$ through a time-invariant linear filter with impulse response $h_{i}(k)$. 


\subsection{Exponential Rule (EXP Rule)}

The EXP Rule [23] is a channel-aware/QoS- aware packet scheduling strategy that was proposed to offer guaranteed QoS to the users over a shared wireless link. The packet scheduler implementing EXP Rule takes into consideration both the channel quality and the states of queues while making scheduling decisions. The following two related rules (EXP-Q and EXP-W) are commonly termed as EXP rule.

The Exponential (Queue length) rule (EXP-Q) selects a single queue for service in time slot $\mathrm{t}$ [23]

$$
i \in i(S(t))=\operatorname{argmax}_{i} \gamma_{i} \mu_{i}(t) \exp \left(\frac{a_{i} Q_{i}(t)}{\beta+[\bar{Q}(t)]^{\eta}}\right)
$$

where $\mu_{i}(t) \equiv \mu_{i}^{m(t)}$ and $\bar{Q}(t) \doteq\left(\frac{1}{N}\right) \sum_{i} a_{i} Q_{i}(t)$

Likewise, the Exponential (Waiting time) rule (EXP-W) selects a queue for service [23]

$$
i \in i(S(t))=\operatorname{argmax}_{i} \gamma_{i} \mu_{i}(t) \exp \left(\frac{a_{i} W_{i}(t)}{\beta+[\bar{W}(t)]^{\eta}}\right)
$$

where $\bar{W}(t) \doteq\left(\frac{1}{N}\right) \sum_{i} a_{i} W_{i}(t)$

Here, $\gamma_{1}, \ldots . \gamma_{N}$ and $a_{1} \ldots . a_{N}$ are arbitrary set of positive constants, $\eta \in(0,1)$ is fixed, and

$\beta$ is positive constant.

\subsection{Logarithmic Rule (LOG Rule)}

LOG Rule, proposed in [24], is a throughput-optimal and channel-aware/queue-aware strategy designed to provide optimised performances in terms of mean delay and robustness. It can be defined as follows.

Let us consider, users' queues are in state q and the channel spectral efficiencies of them are $\boldsymbol{K} \equiv$ $\left(K_{i}: 1 \leq i \leq N\right)$, then according to LOG rule, the scheduler will serve a user $\mathrm{i}_{\mathrm{LOG}}$ [25]:

$$
i_{L O G}(q, K) \in \arg \max _{1 \leq i \leq N} b_{i} \log \left(c+a_{i} Q_{i}\right) \times K_{i}
$$

where, $b_{i}, a_{i}, c$ are fixed positive constants, $0<\eta<1$, and $Q_{i}$ represents the queue length.

\section{SimUlations AND RESUlTS}

In this section, the performance of PF, M-LWDF, EXP/PF, EXP-Rule, FLS, and LOG-Rule packet scheduling algorithms are analysed and compared based on several performance metrics such as packet delay, PLR (Packet Loss Ratio), average throughput, and spectral efficiency for different users' speeds. An open source simulator namely LTE-Sim [7] has been adopted to perform simulations.

\subsection{Simulation Scenario}

A single urban macro cell of radius $1 \mathrm{Km}$ with interference scenario is modelled to study the performances of the considered scheduling schemes. A number of users ranging from 10 to 100 are uniformly distributed throughout the cell and moving with constant speed in random direction 
International Journal of Wireless \& Mobile Networks (IJWMN) Vol. 7, No. 5, October 2015

within the cell. Each user receives one best effort (BE) flow, one VoIP flow and one video flow simultaneously. Three different speeds of $3 \mathrm{~km} / \mathrm{h}, 30 \mathrm{~km} / \mathrm{h}$ and $120 \mathrm{~km} / \mathrm{h}$ are considered in order to evaluate the performances upon varying users' speed. The simulation parameters are summarized in Table 1.

Table 1: Simulation Parameters

\begin{tabular}{|l|l|}
\hline \multicolumn{1}{|c|}{ Parameters } & \multicolumn{1}{c|}{ Values } \\
\hline Simulation time & $100 \mathrm{sec}$ \\
\hline Flow duration & $80 \mathrm{sec}$ \\
\hline Cell radius & $1 \mathrm{~km}$ \\
\hline User speed & $3 \mathrm{~km} / \mathrm{h}, 30 \mathrm{~km} / \mathrm{h}$, and $120 \mathrm{~km} / \mathrm{h}$ \\
\hline Video bit rate & $242 \mathrm{kbps}$ \\
\hline Frame structure & FDD \\
\hline Bandwidth & $10 \mathrm{MHz}$ \\
\hline Maximum delay & $0.1 \mathrm{sec}$ \\
\hline
\end{tabular}

\subsection{Result Analysis}

The VoIP delay graphs for $3 \mathrm{~km} / \mathrm{h}, 30 \mathrm{~km} / \mathrm{h}$ and $120 \mathrm{~km} / \mathrm{h}$ users' speeds are depicted in Fig. 3. As seen, on average, the packet delay for VoIP flow gradually increases while the number of users increases from 10 to 100 and users' speed increases from $3 \mathrm{~km} / \mathrm{h}$ to $120 \mathrm{~km} / \mathrm{h}$ for all packet scheduling algorithms. For 100 users, the highest delay is experienced with PF algorithm and the lowest upper bound of delay is observed for FLS algorithm for all three user-speed cases. With $120 \mathrm{~km} / \mathrm{h}$ users' speed, packet delay for PF algorithm noticeably increases when the cell is charged with more than 40 users and it becomes $3.6 \mathrm{sec}$ when there are 100 users in the cell.

Fig. 4, showing the video delay graphs for three different users' speeds, illustrates that video delay increases with increasing number of users and users' speed for all simulated scheduling schemes with relatively sharp delay increase in case of PF algorithm as compared with other algorithms for all user-speed cases.

Fig. 5 shows that the VoIP packet loss ratio increases with increasing number of users and FLS provides smallest PLR compared with other simulated scheduling schemes. The PLR of VoIP flow is also increased while users' speed is increased from $3 \mathrm{~km} / \mathrm{h}$ to $120 \mathrm{~km} / \mathrm{h}$. For 100 users, packet loss ratios for PF, M-LWDF, EXP/PF, EXP, LOG, and FLS scheduling schemes are 45\%, $39.5 \%, 39.7 \%, 33.5 \%, 38.9 \%$, and $11.2 \%$ respectively when users are moving at vehicular speed$120 \mathrm{~km} / \mathrm{h}$, whereas, with pedestrian speed of $3 \mathrm{~km} / \mathrm{h}$, PLR values are $8.3 \%, 6.4 \%, 7 \%, 3 \%, 6.5 \%$, and $<1 \%$ respectively.

The video PLR graphs in Fig. 6 depict that PLR of PF algorithm higher than other scheduling schemes irrespective of user number and speed at which users move in. It is also noticed that for all three user-speed case, FLS algorithm provides lowest PLR for each user number. Comparing Fig. 5 and Fig. 6, it is seen that for multimedia flows, PLR increases with increasing number of users and users' speed for all schemes, and EXP/PF and LOG Rule show almost same PLR performance regardless of users' speed.

The average throughput graph for VoIP flow shows that for $3 \mathrm{~km} / \mathrm{h}$ of users' speed (shown in Fig. 7), the average throughput remains almost constant at around 3000bps while the number of users lies in the range of 10 to 70 followed by slight decrease in average throughput when the cell is charged with more than 70 users, for all algorithms. When the user's speed is increased to $120 \mathrm{~km} / \mathrm{h}$, average throughput maintains almost same level at 3000bps in the user range of [10-20] 
International Journal of Wireless \& Mobile Networks (IJWMN) Vol. 7, No. 5, October 2015

after which it degrades with increasing number of users, and FLS shows best throughput performance.

From Fig. 8, it is noticed that the average throughput for video flow decreases with increasing user number and user speed. It is observed that in case of user' speed of $120 \mathrm{~km} / \mathrm{h}$, there is more rapid decrease in average throughput with increasing number of users as compared with lower users' speed such as $3 \mathrm{~km} / \mathrm{h}$ or $30 \mathrm{~km} / \mathrm{h}$ case. For all users' speed cases, FLS is showing best performance and $\mathrm{PF}$ algorithm is showing worst performance in terms of average throughput.

As seen from Fig. 9, for BE flow, PF, M-LWDF, EXP/PF and LOG Rule show almost similar performance irrespective of users' speed and number of users, and FLS scheme shows worst performance among the six schemes being considered. It is also observed that average throughput decreases with increasing users' speed, for example, the upper bounds of average throughput for FLS scheme are 165.06kbps, 137.16kbps, and 71.34kbps for users' speed $3 \mathrm{~km} / \mathrm{h}$, $30 \mathrm{~km} / \mathrm{h}$, and $120 \mathrm{~km} / \mathrm{h}$ respectively.

The decreasing trend of average throughput with increasing user's speed is due to fact that higher speed can result in worse channel quality being measured by users, which in turn causes lower order MCS to be selected to transmit data packets i.e. lower bits are transmitted per modulation symbol, which yields in lower average throughput .

Fig. 10 illustrates that the cell spectral efficiency (bits/sec/Hz) degrades with increasing users' speed. For FLS scheme, the upper bounds of spectral efficiency are $0.20,0.17$ and 0.12 for speed $3 \mathrm{~km} / \mathrm{h}, 30 \mathrm{~km} / \mathrm{h}$ and $120 \mathrm{~km} / \mathrm{h}$ respectively.

Considering above analysis, it can be concluded that for real-time traffic, FLS scheme is more suitable, in terms of delay, PLR and average throughput performance metrics, as compared with leftover schemes being considered here, and PF algorithms is not suitable as it shows higher PLR and packet delay, and lower average throughput compared with other schemes. On the other hand, for BE flow, FLS scheme shows worst performance in terms of average throughput. For BE flow, EXP/PF provides better average throughput performance compared with other five schemes.

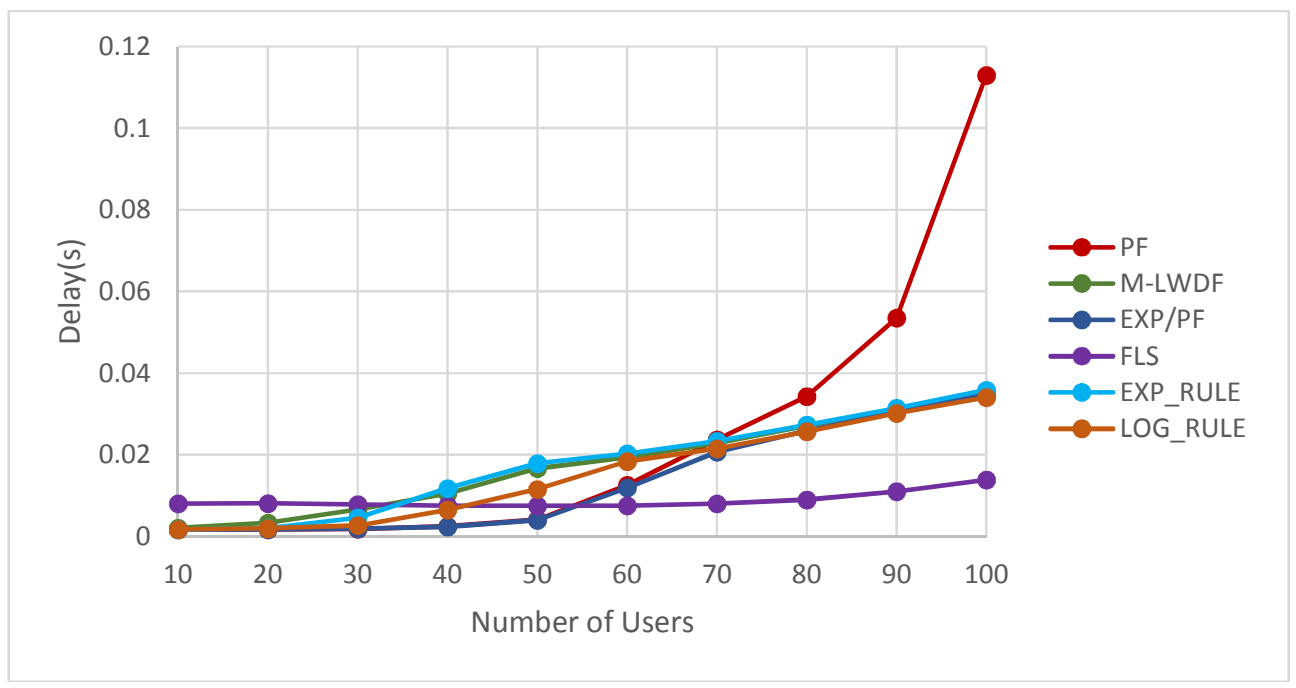

(a) 
International Journal of Wireless \& Mobile Networks (IJWMN) Vol. 7, No. 5, October 2015

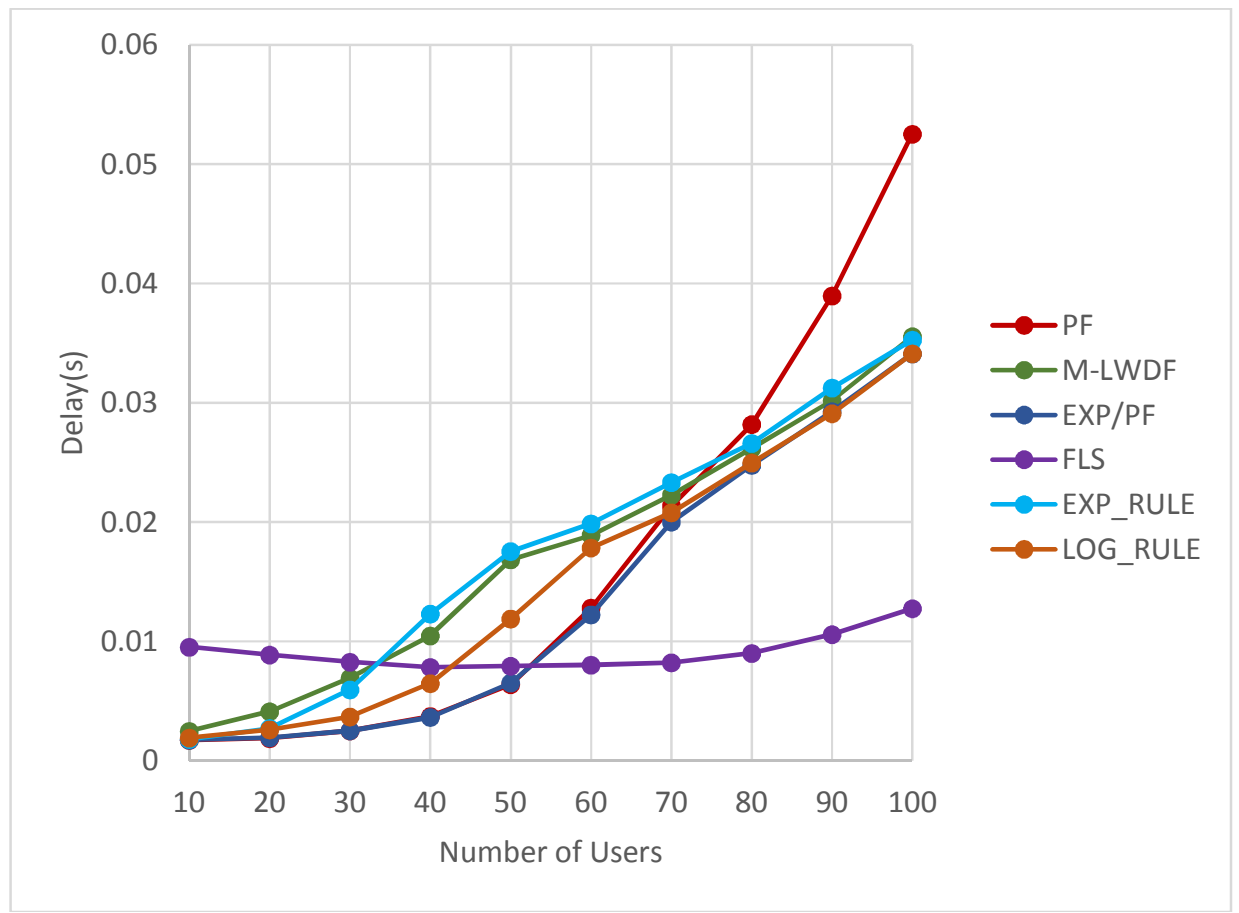

(b)

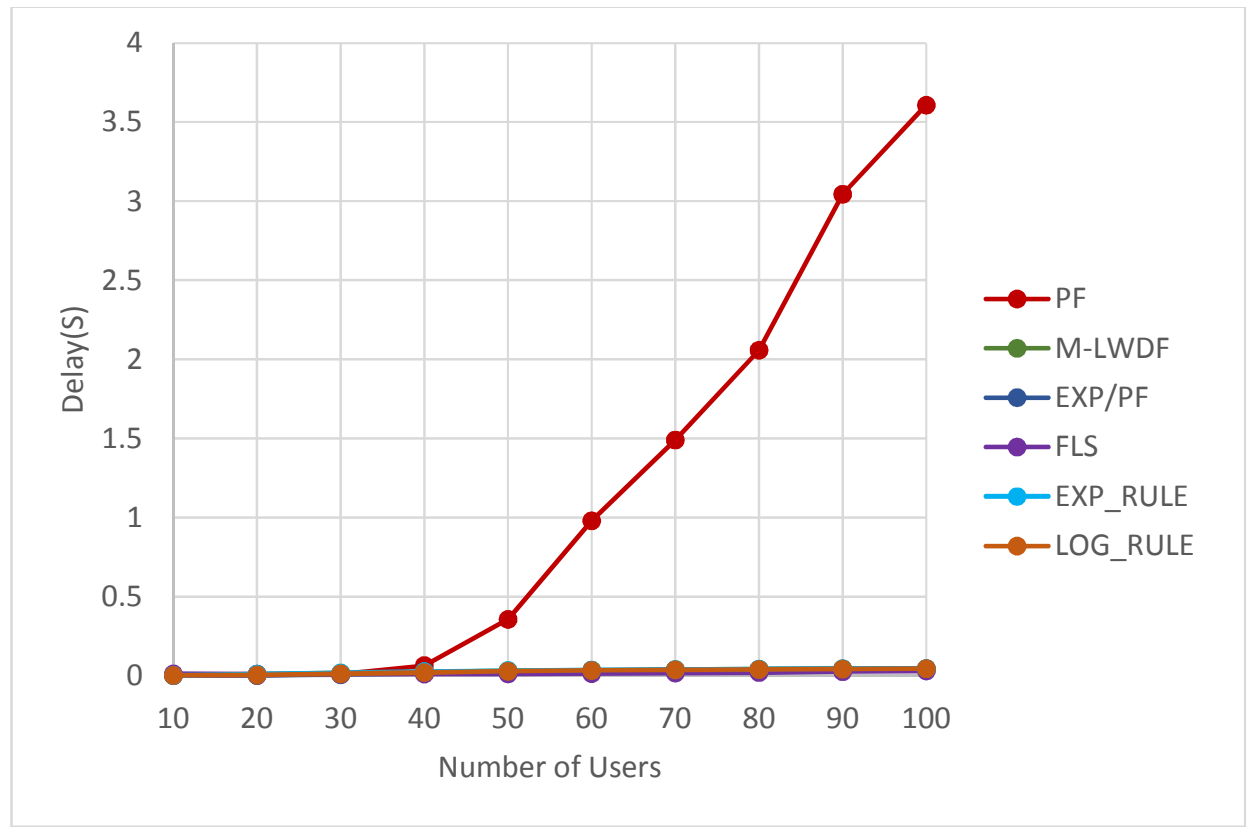

(c)

Figure 3: VoIP delay for different users' speed (a) $3 \mathrm{~km} / \mathrm{h}$ (b) $30 \mathrm{~km} / \mathrm{h}$ (c) $120 \mathrm{~km} / \mathrm{h}$ 
International Journal of Wireless \& Mobile Networks (IJWMN) Vol. 7, No. 5, October 2015

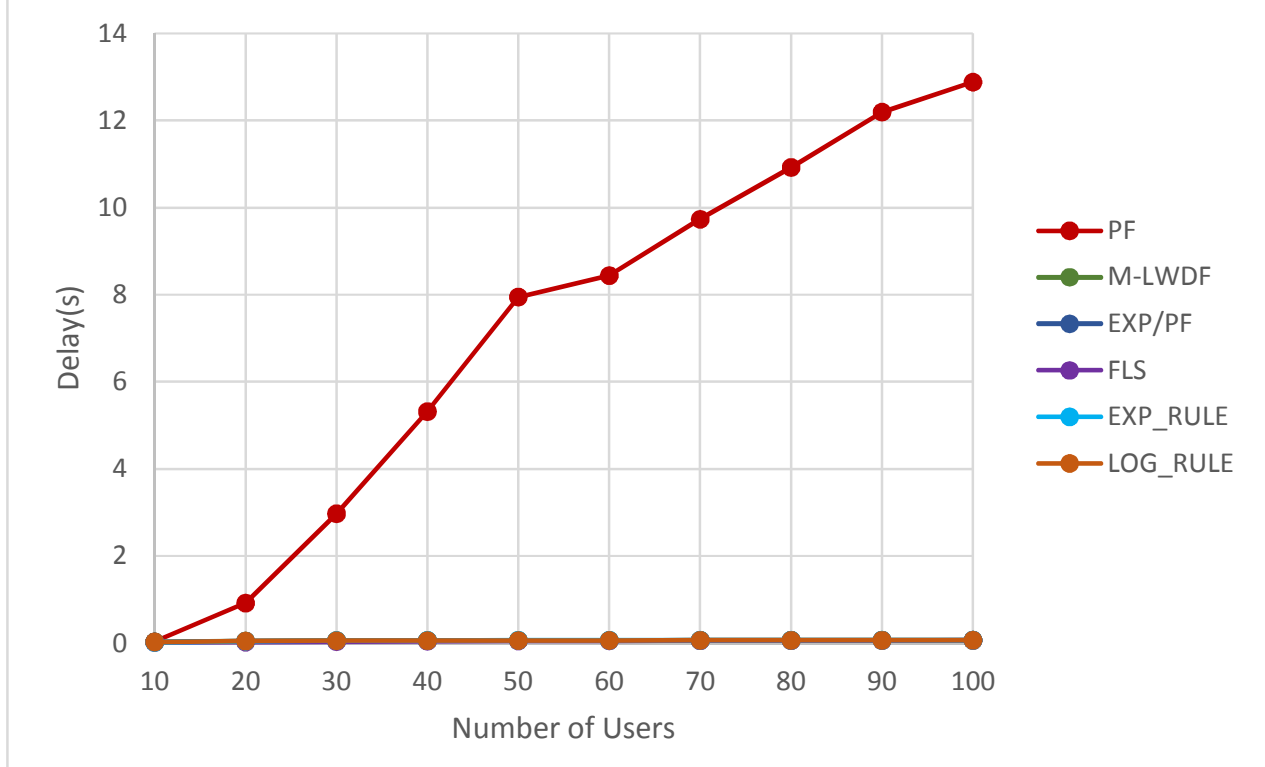

(a)

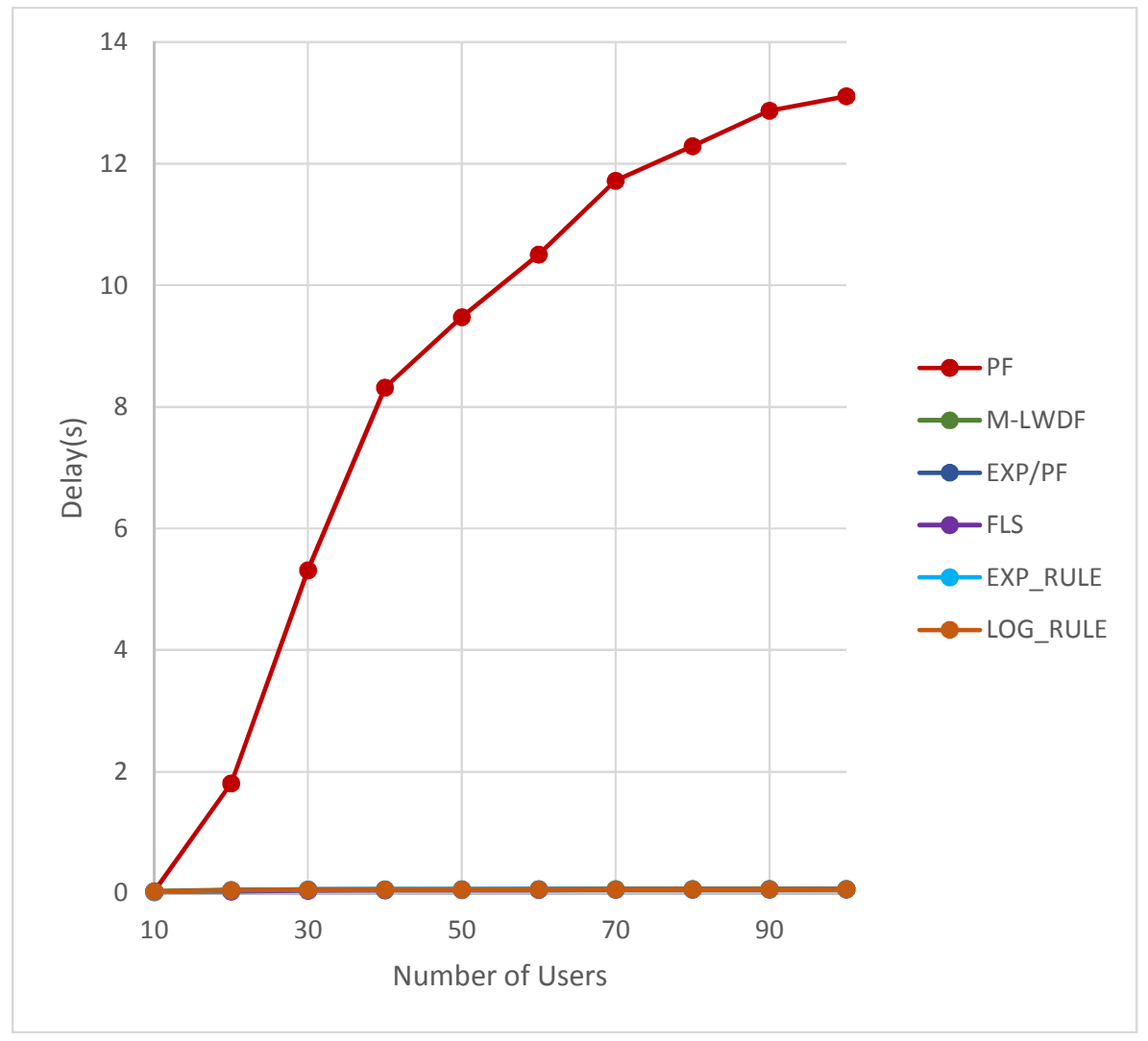

(b) 
International Journal of Wireless \& Mobile Networks (IJWMN) Vol. 7, No. 5, October 2015

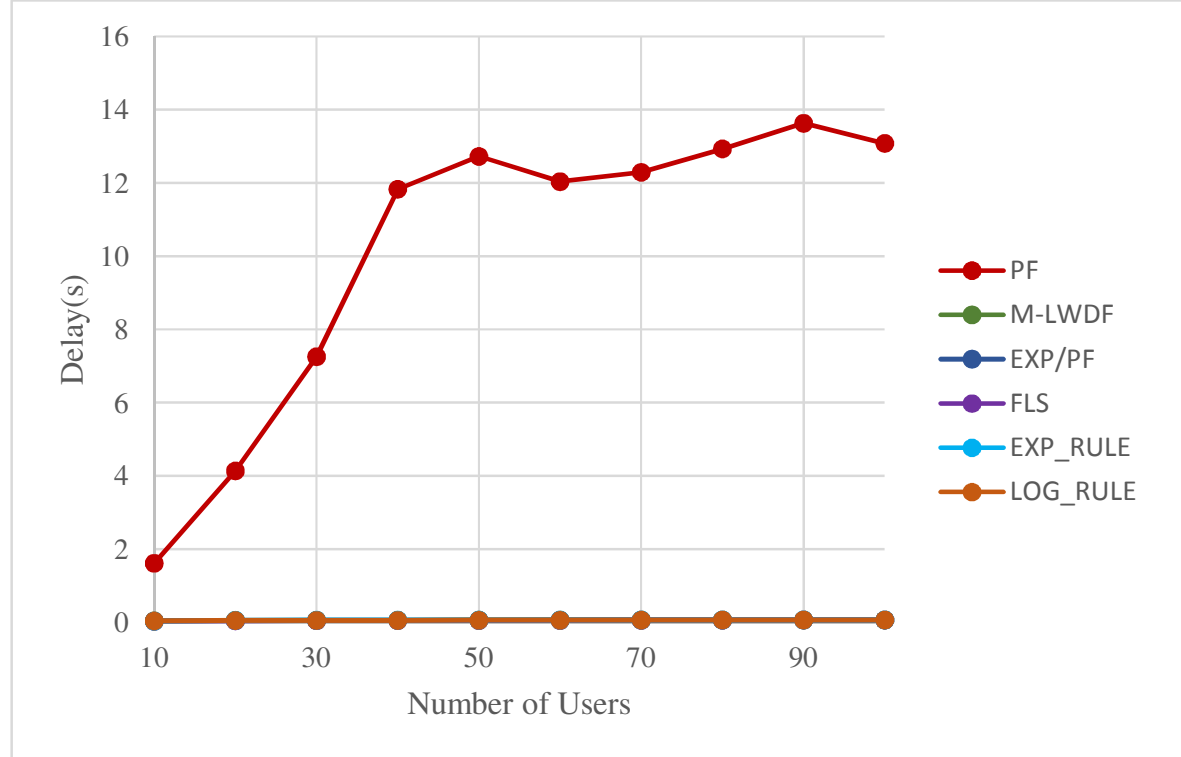

(c)

Figure 4: Video delay for different users' speed (a) $3 \mathrm{~km} / \mathrm{h}$ (b) $30 \mathrm{~km} / \mathrm{h}$ (c) $120 \mathrm{~km} / \mathrm{h}$

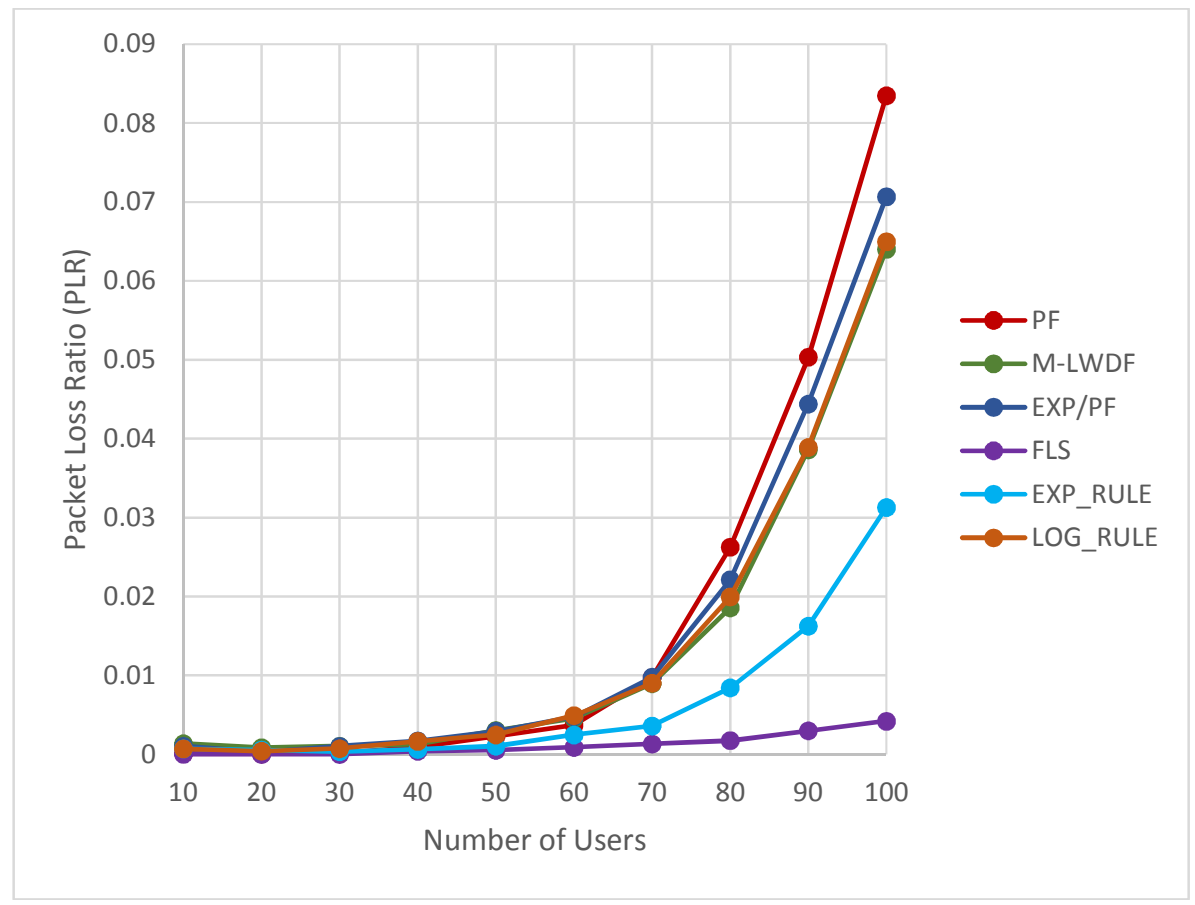

(a) 
International Journal of Wireless \& Mobile Networks (IJWMN) Vol. 7, No. 5, October 2015

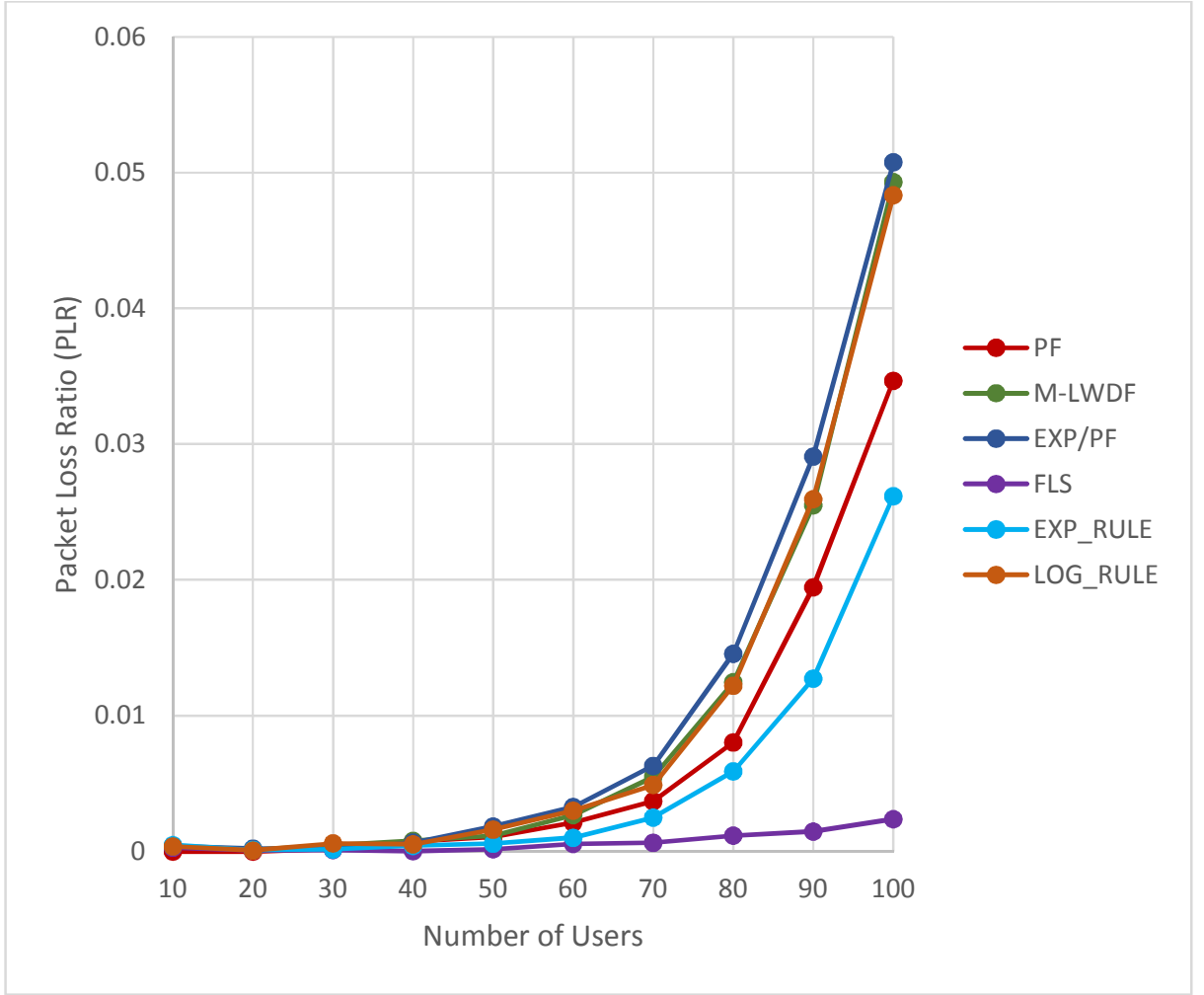

(b)

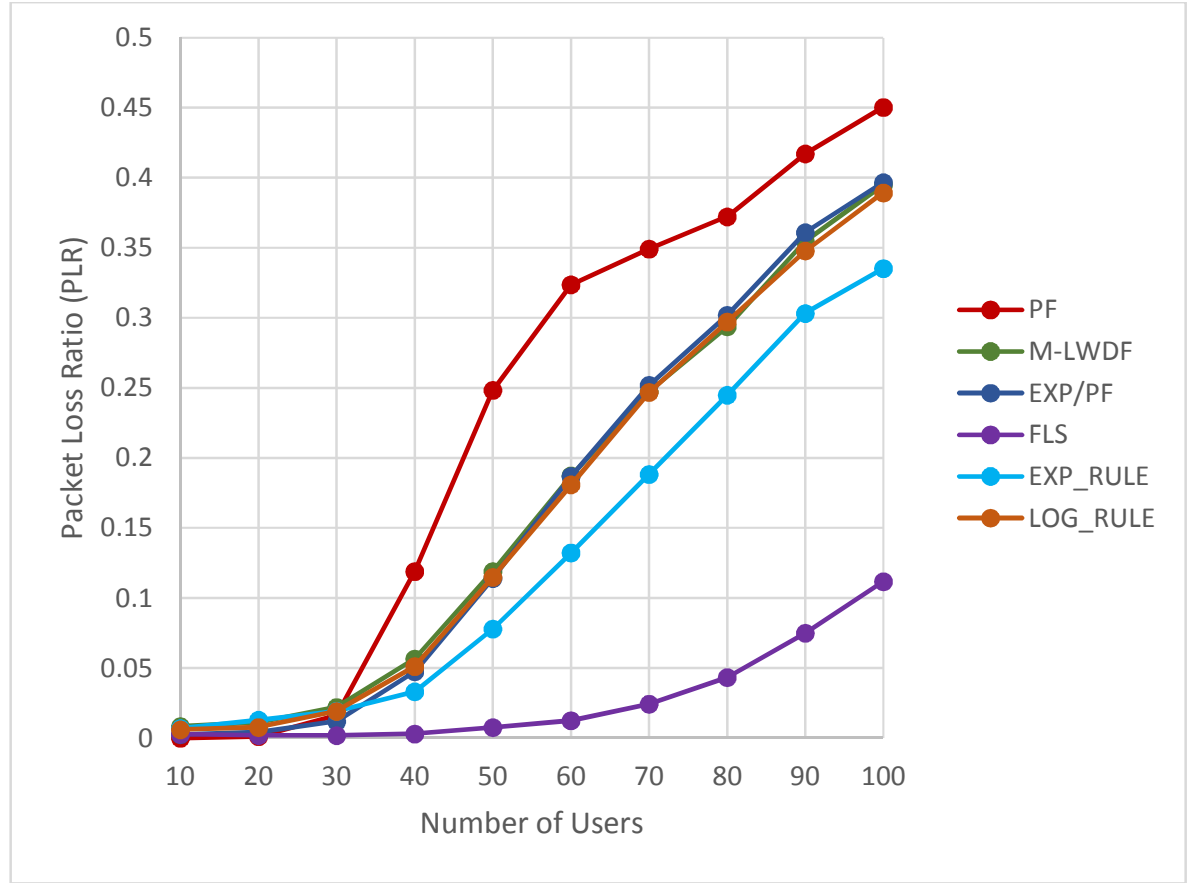

(c)

Figure 5: VoIP PLR for different users' speed (a) $3 \mathrm{~km} / \mathrm{h}$ (b) $30 \mathrm{~km} / \mathrm{h}$ (c) $120 \mathrm{~km} / \mathrm{h}$ 
International Journal of Wireless \& Mobile Networks (IJWMN) Vol. 7, No. 5, October 2015

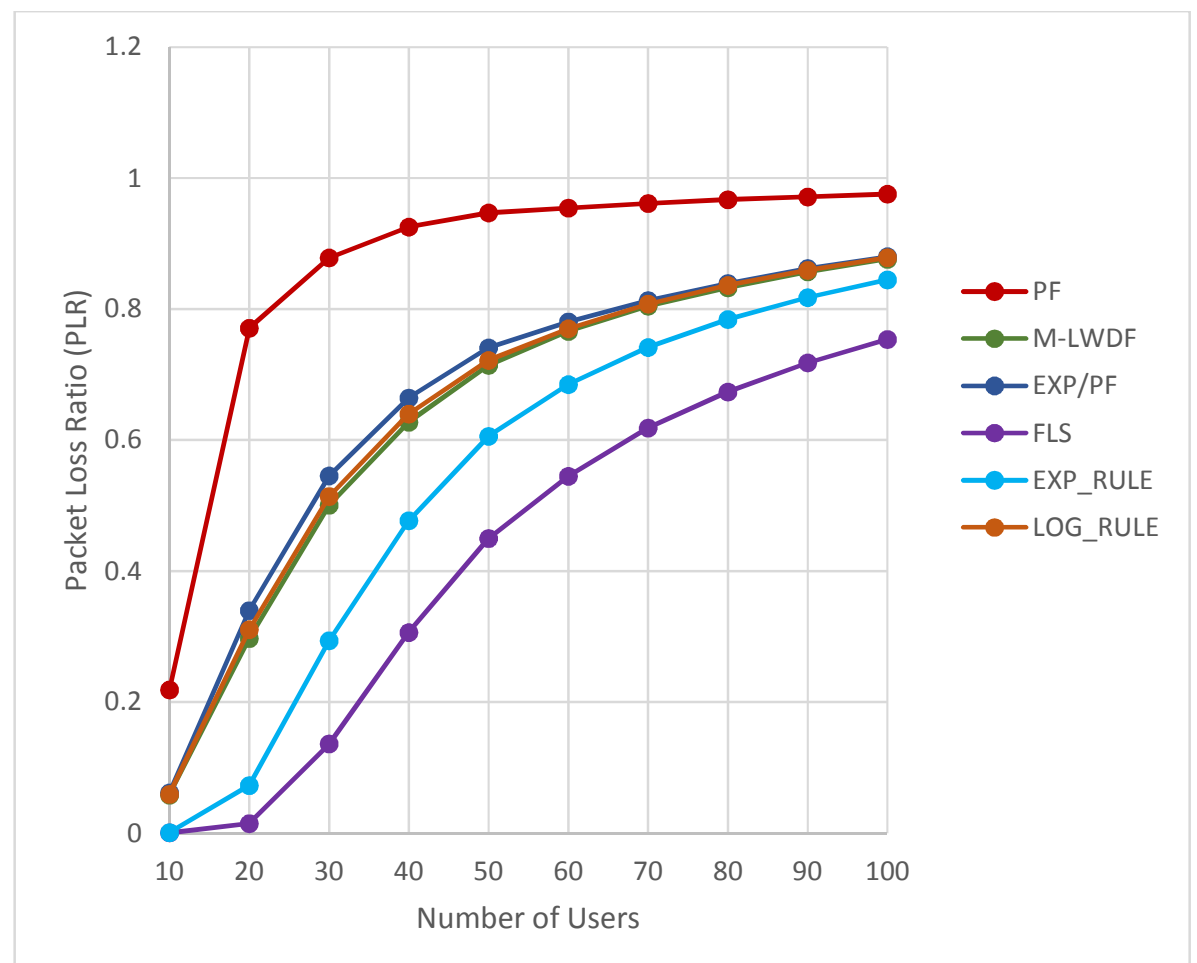

(a)

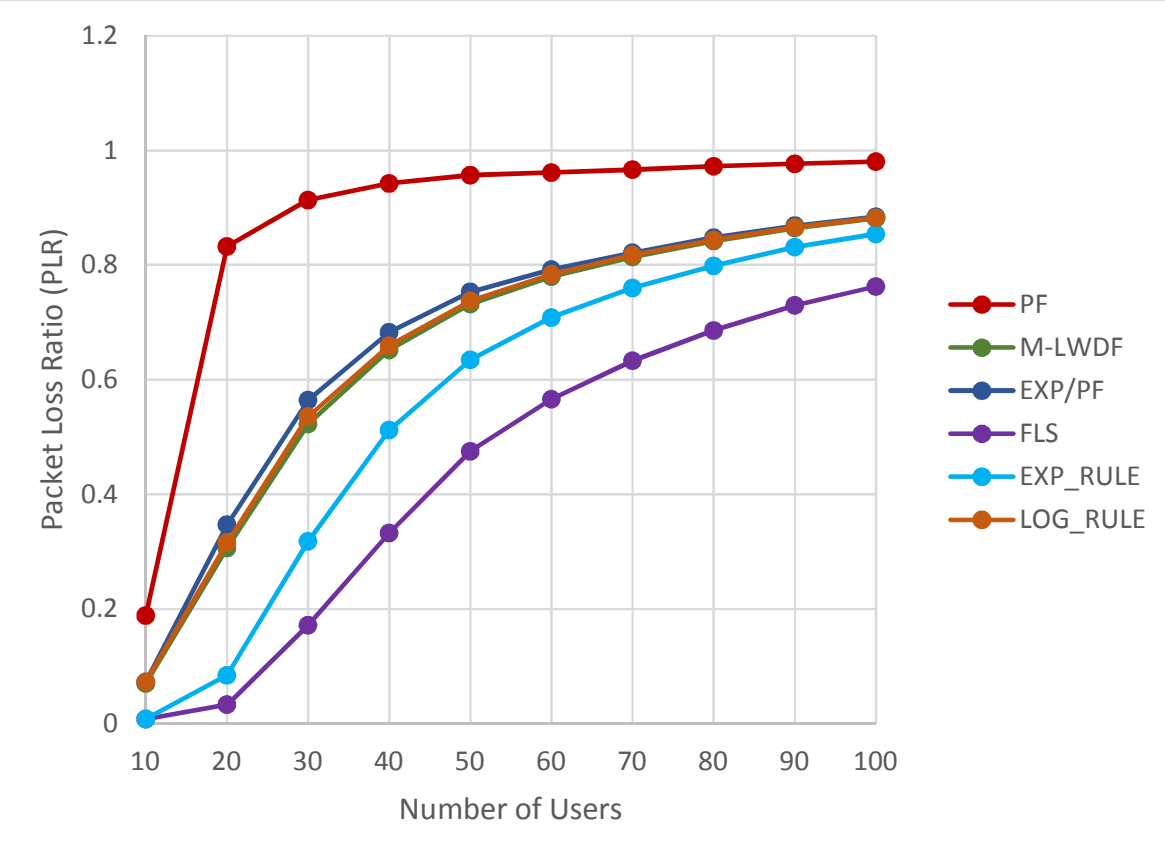

(b) 
International Journal of Wireless \& Mobile Networks (IJWMN) Vol. 7, No. 5, October 2015

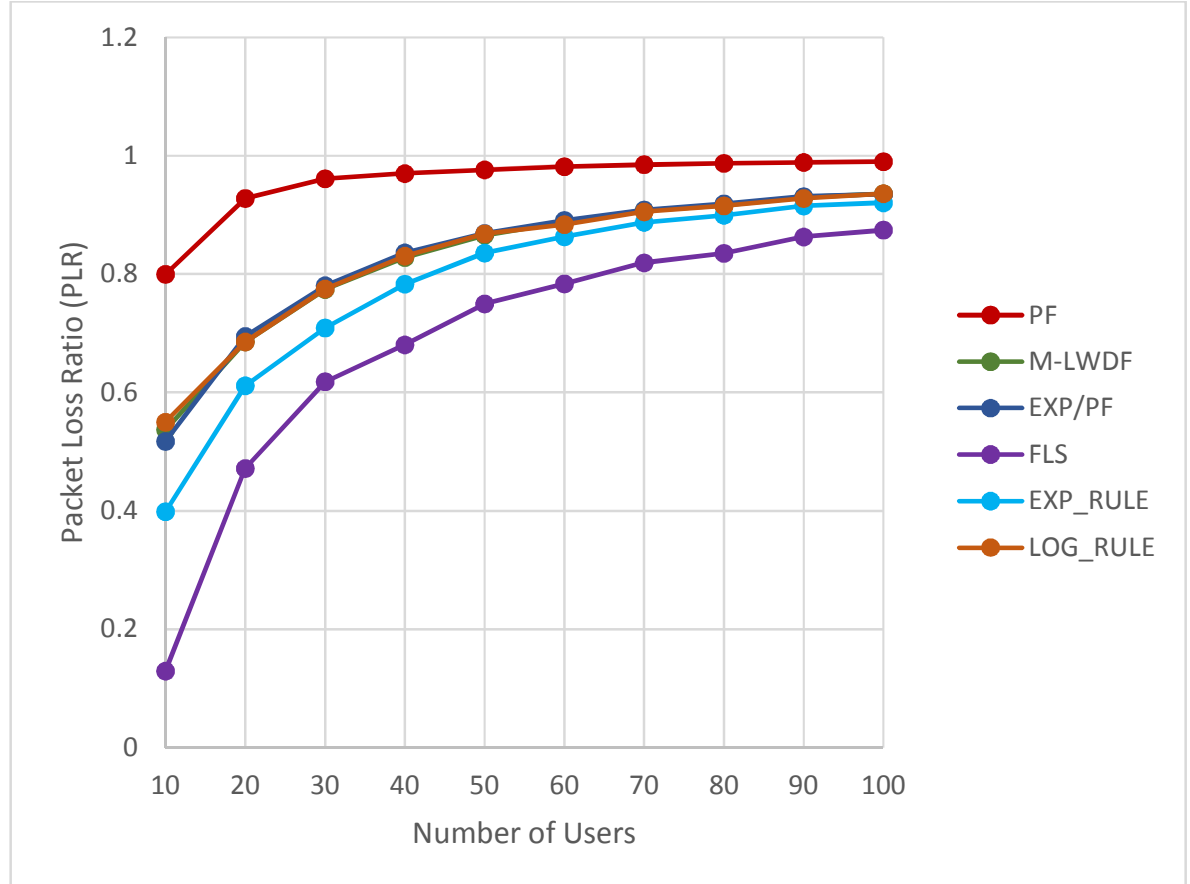

(c)

Figure 6: Video PLR for different users' speed (a) $3 \mathrm{~km} / \mathrm{h}$ (b) $30 \mathrm{~km} / \mathrm{h}$ (c) $120 \mathrm{~km} / \mathrm{h}$

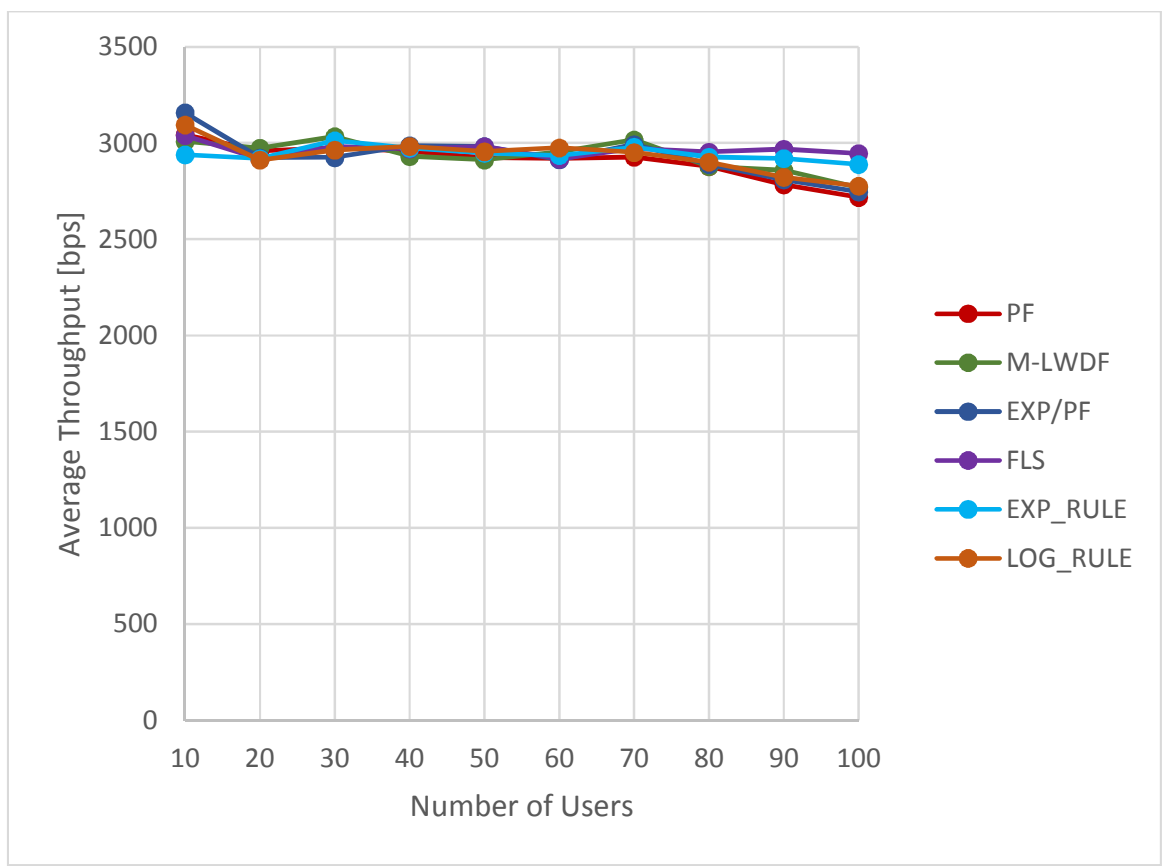

(a) 
International Journal of Wireless \& Mobile Networks (IJWMN) Vol. 7, No. 5, October 2015

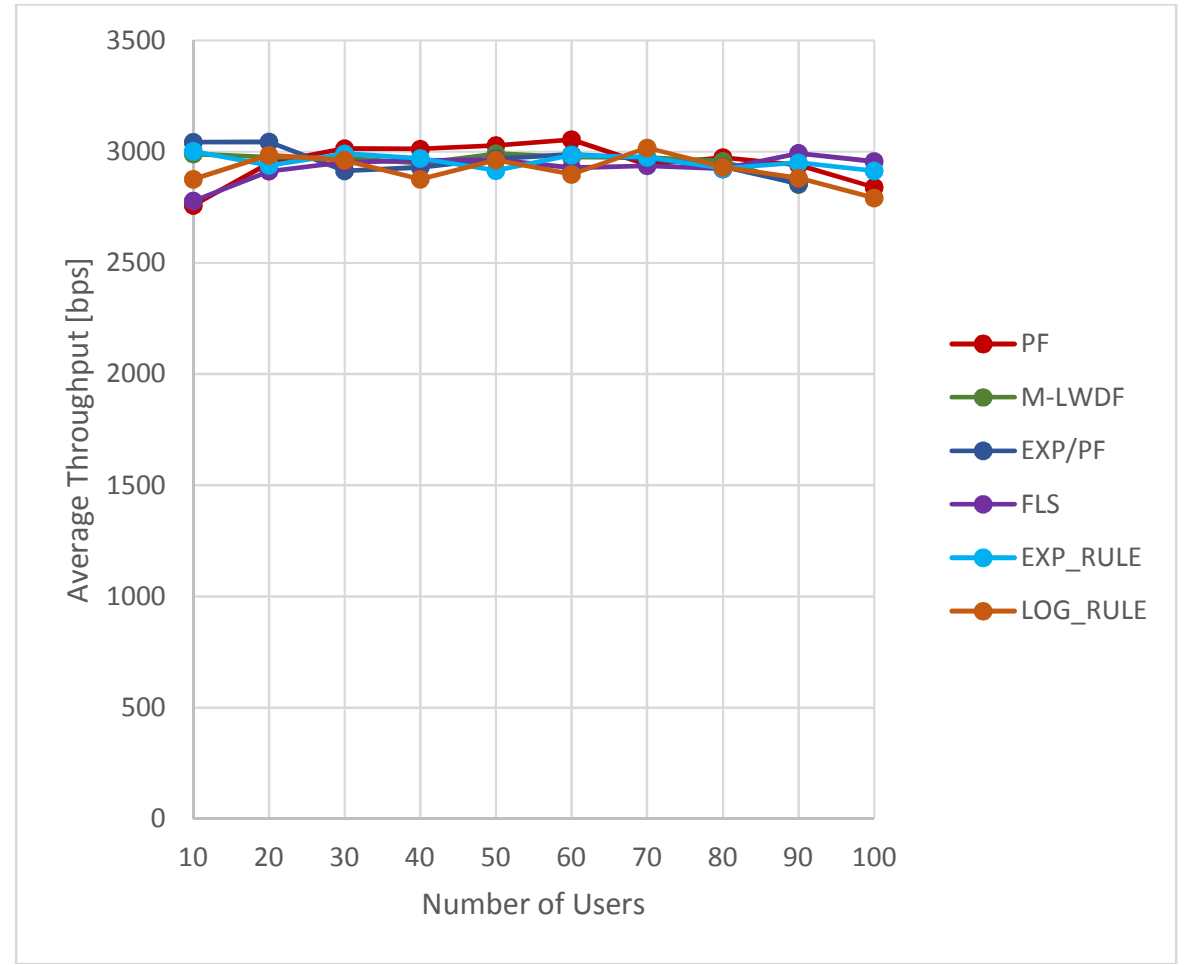

(b)

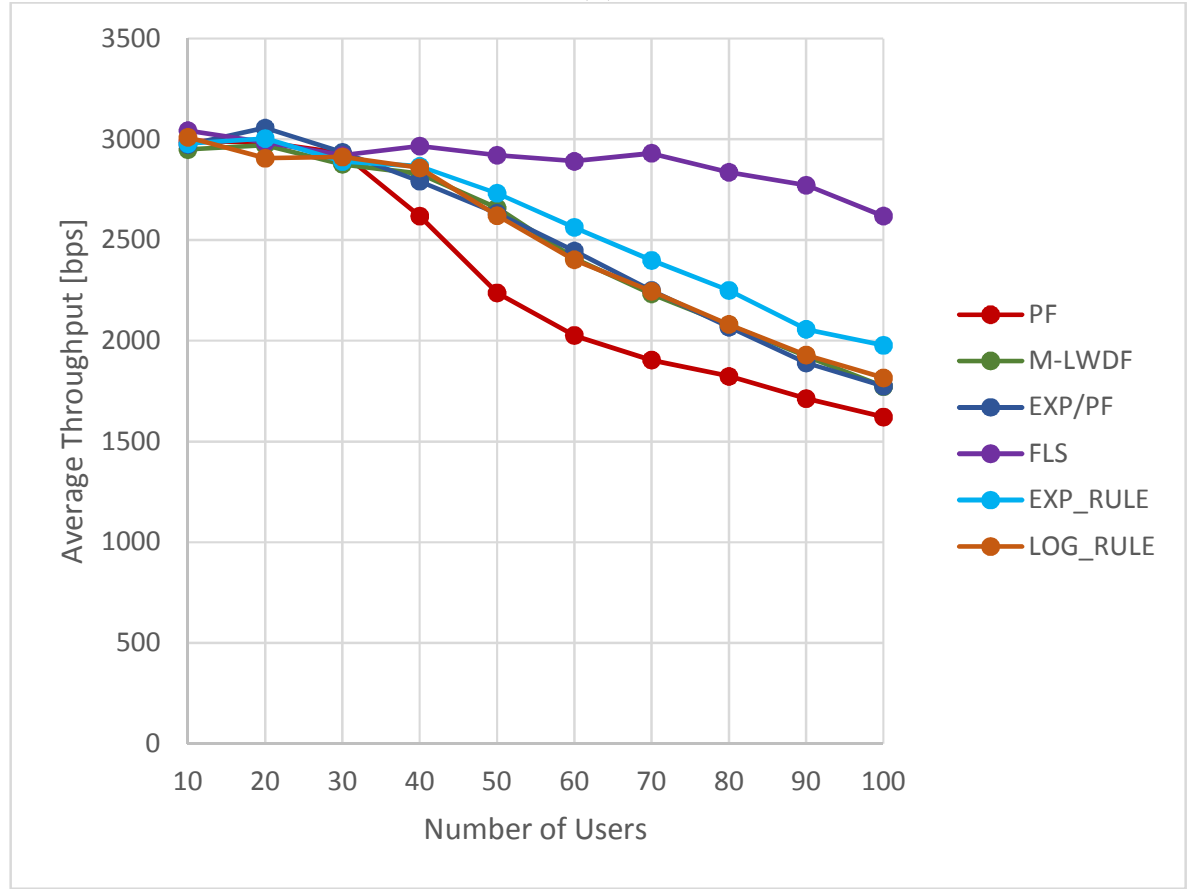

(c)

Figure 7: VoIP average throughput for different users' speed (a) $3 \mathrm{~km} / \mathrm{h}$ (b) $30 \mathrm{~km} / \mathrm{h}$ (c) $120 \mathrm{~km} / \mathrm{h}$ 
International Journal of Wireless \& Mobile Networks (IJWMN) Vol. 7, No. 5, October 2015

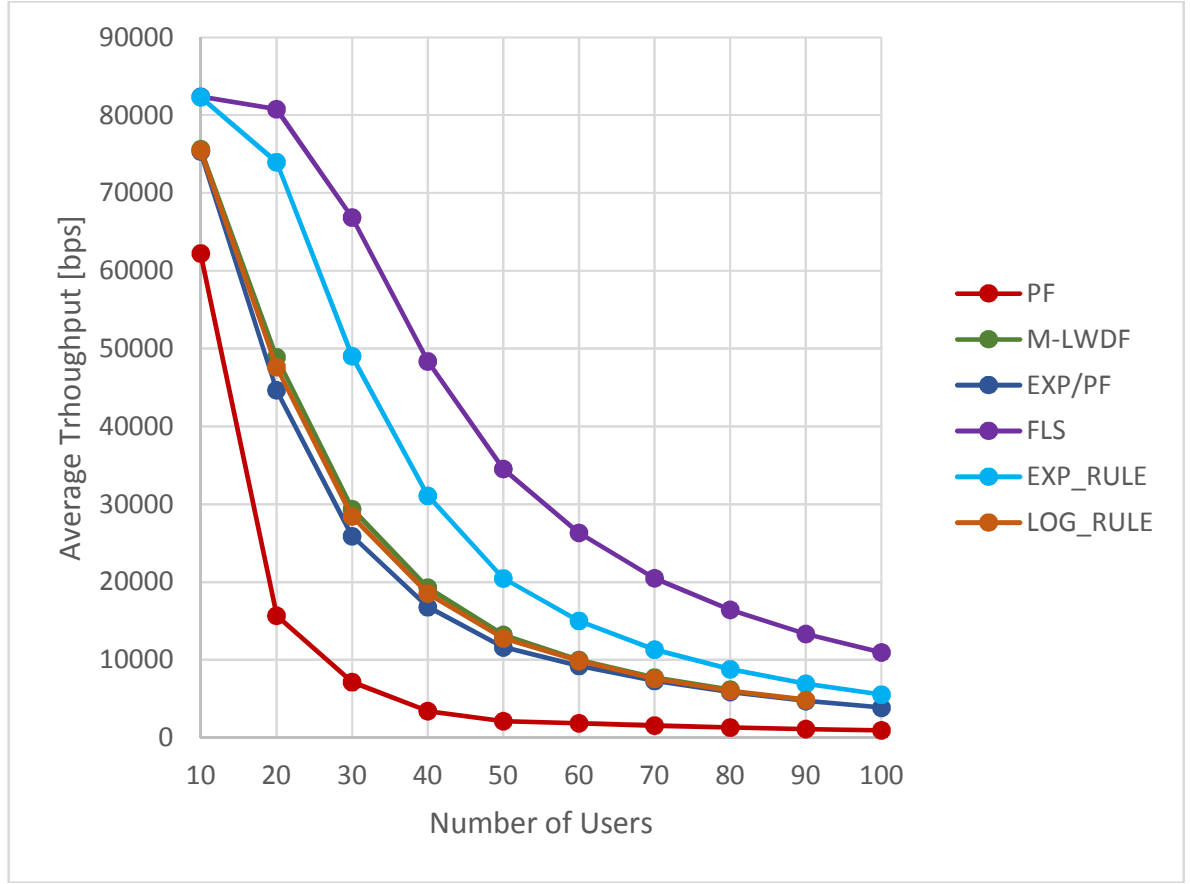

(a)

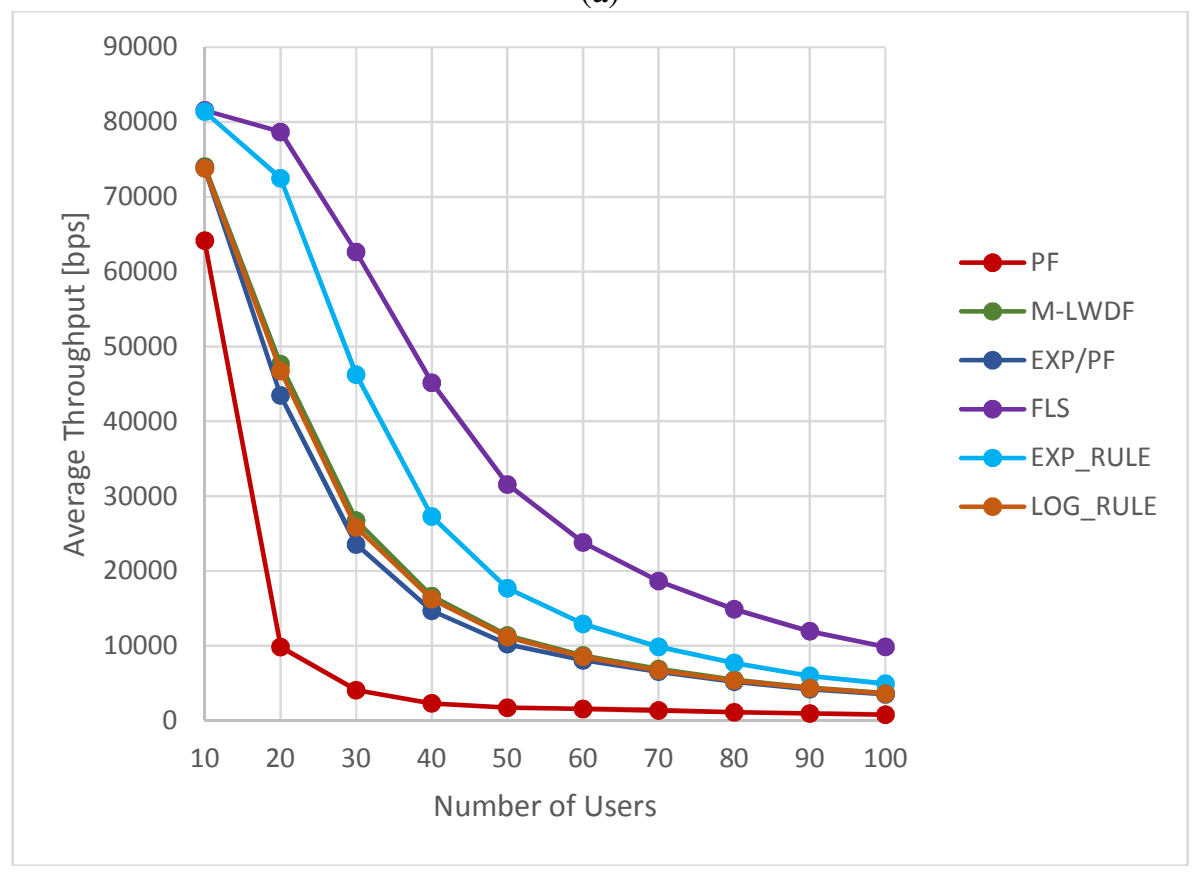

(b) 
International Journal of Wireless \& Mobile Networks (IJWMN) Vol. 7, No. 5, October 2015

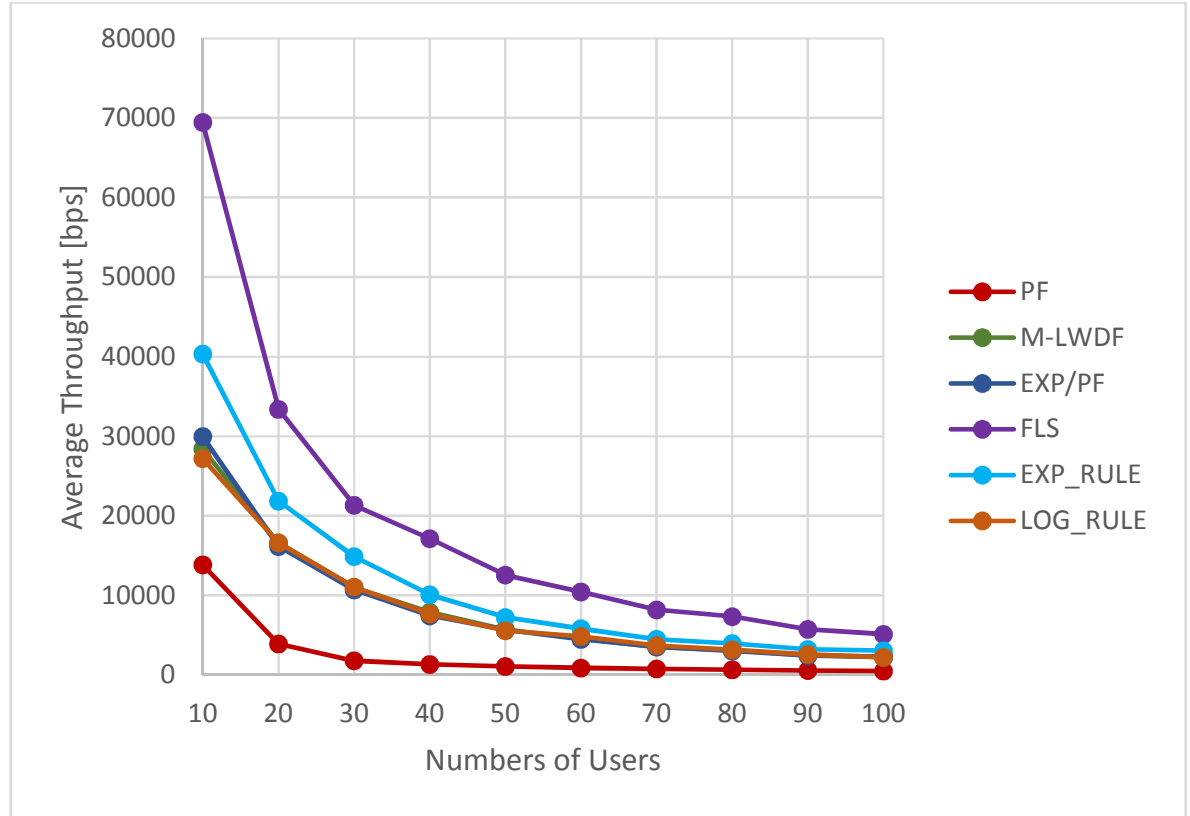

(c)

Figure 8: Video average throughput for different users' speed (a) $3 \mathrm{~km} / \mathrm{h}$ (b) $30 \mathrm{~km} / \mathrm{h}$ (c) $120 \mathrm{~km} / \mathrm{h}$

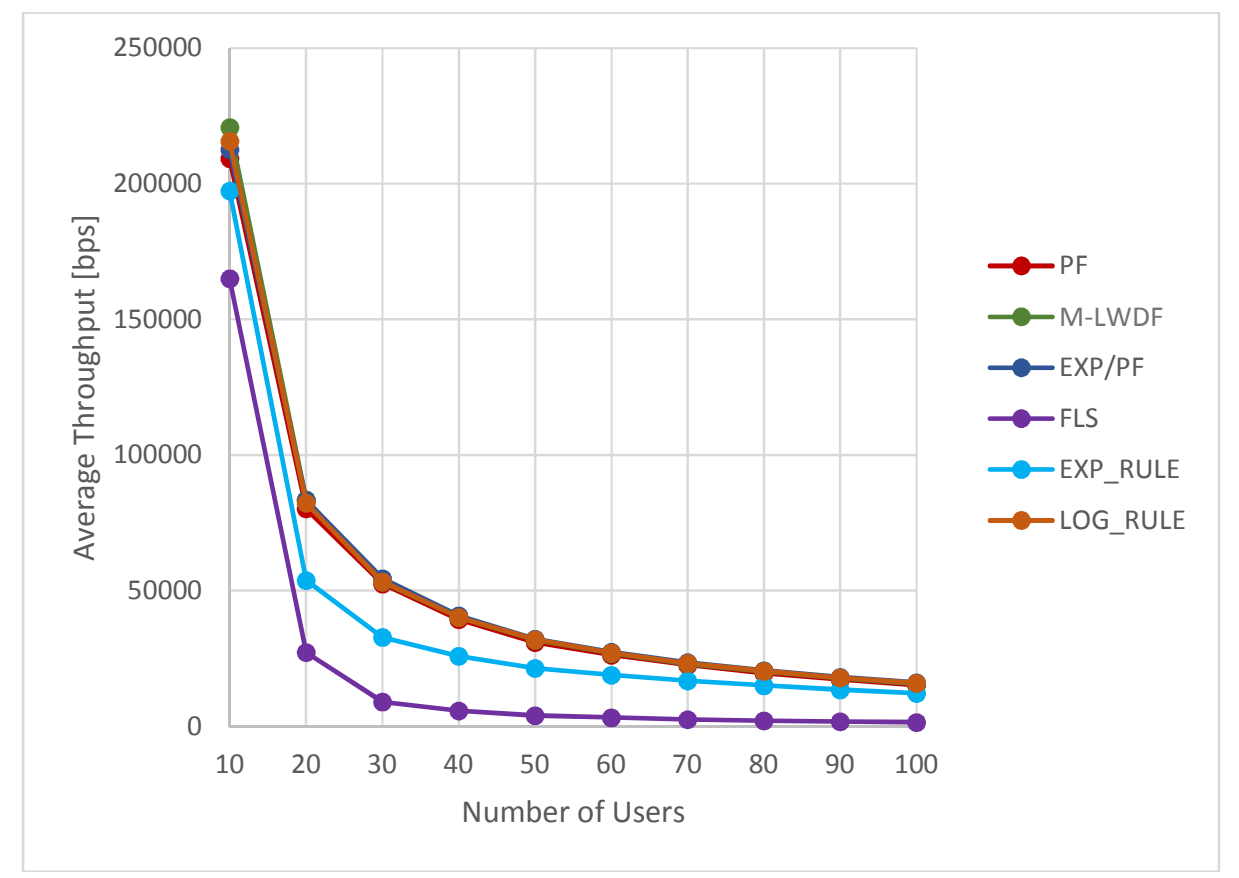

(a) 
International Journal of Wireless \& Mobile Networks (IJWMN) Vol. 7, No. 5, October 2015

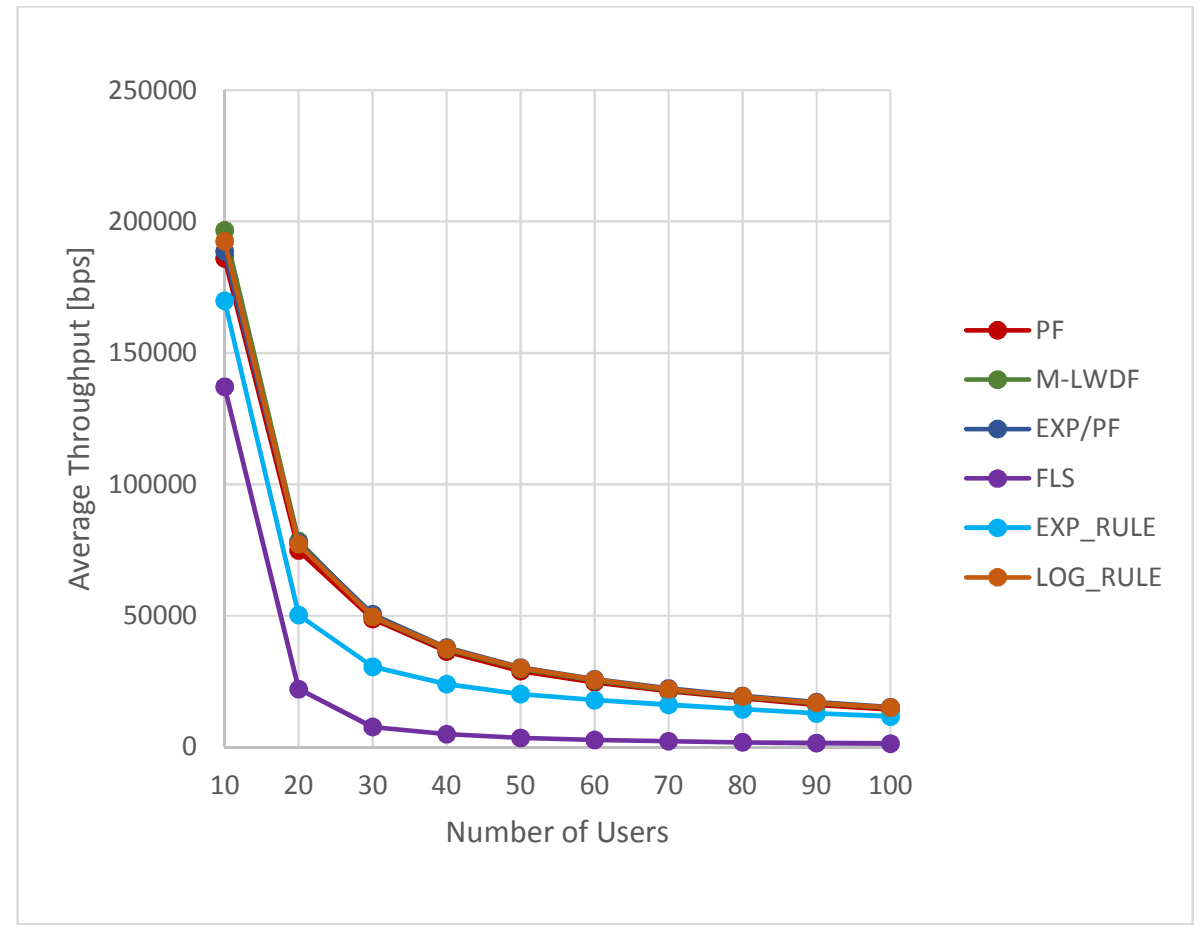

(b)

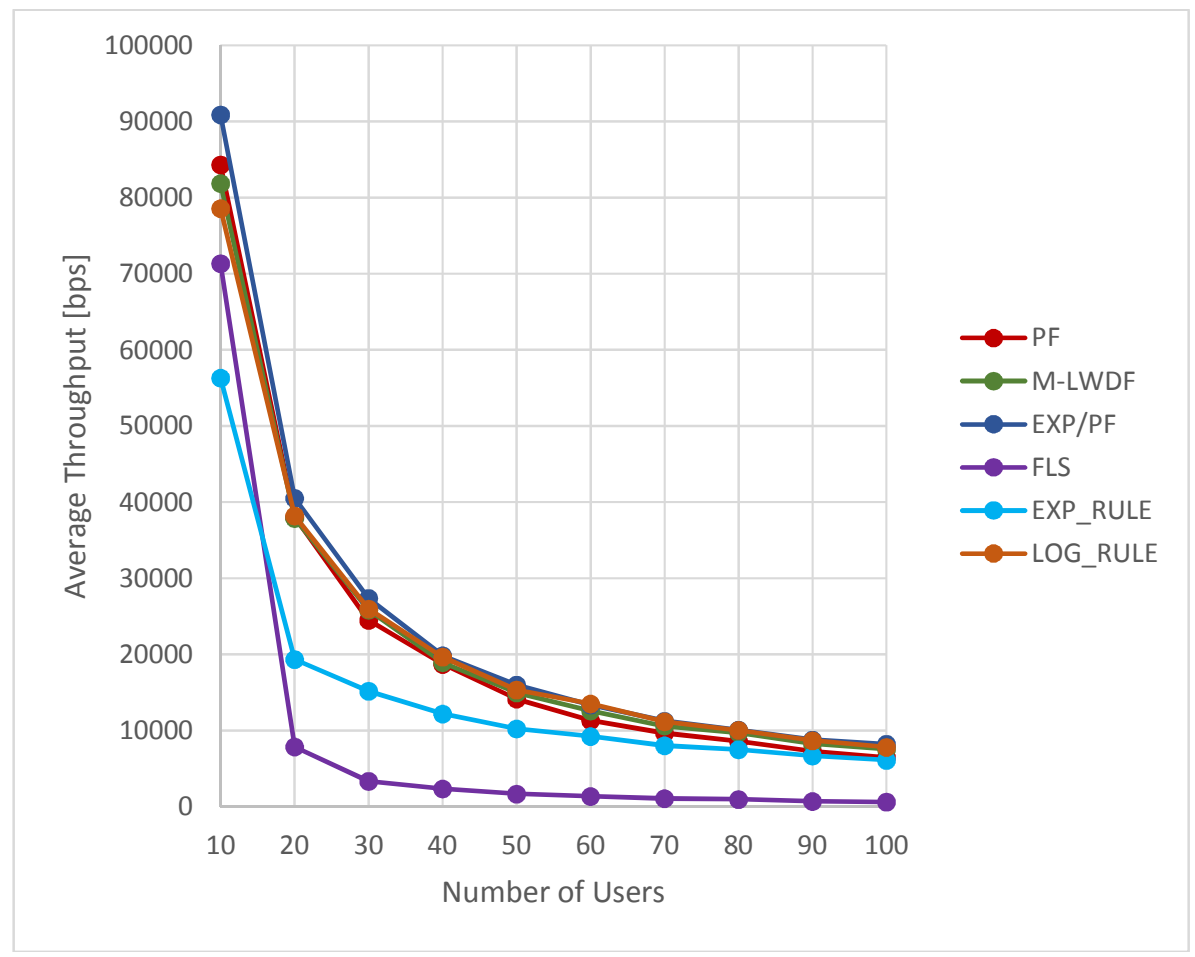

(c)

Figure 9: Average throughput of BE flow for different speed (a) $3 \mathrm{~km} / \mathrm{h}$ (b) $30 \mathrm{~km} / \mathrm{h}$ (c) $120 \mathrm{~km} / \mathrm{h}$ 
International Journal of Wireless \& Mobile Networks (IJWMN) Vol. 7, No. 5, October 2015

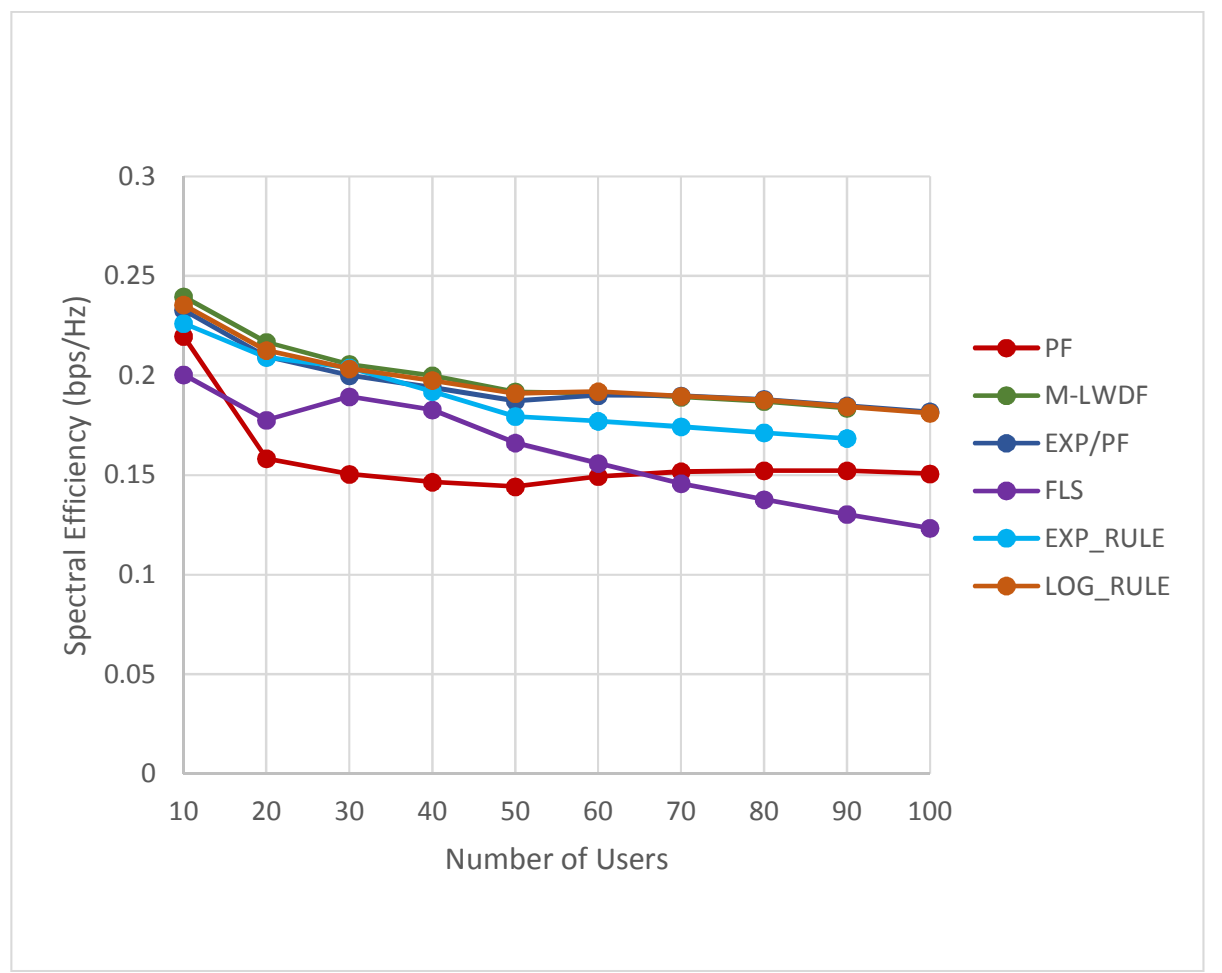

(a)

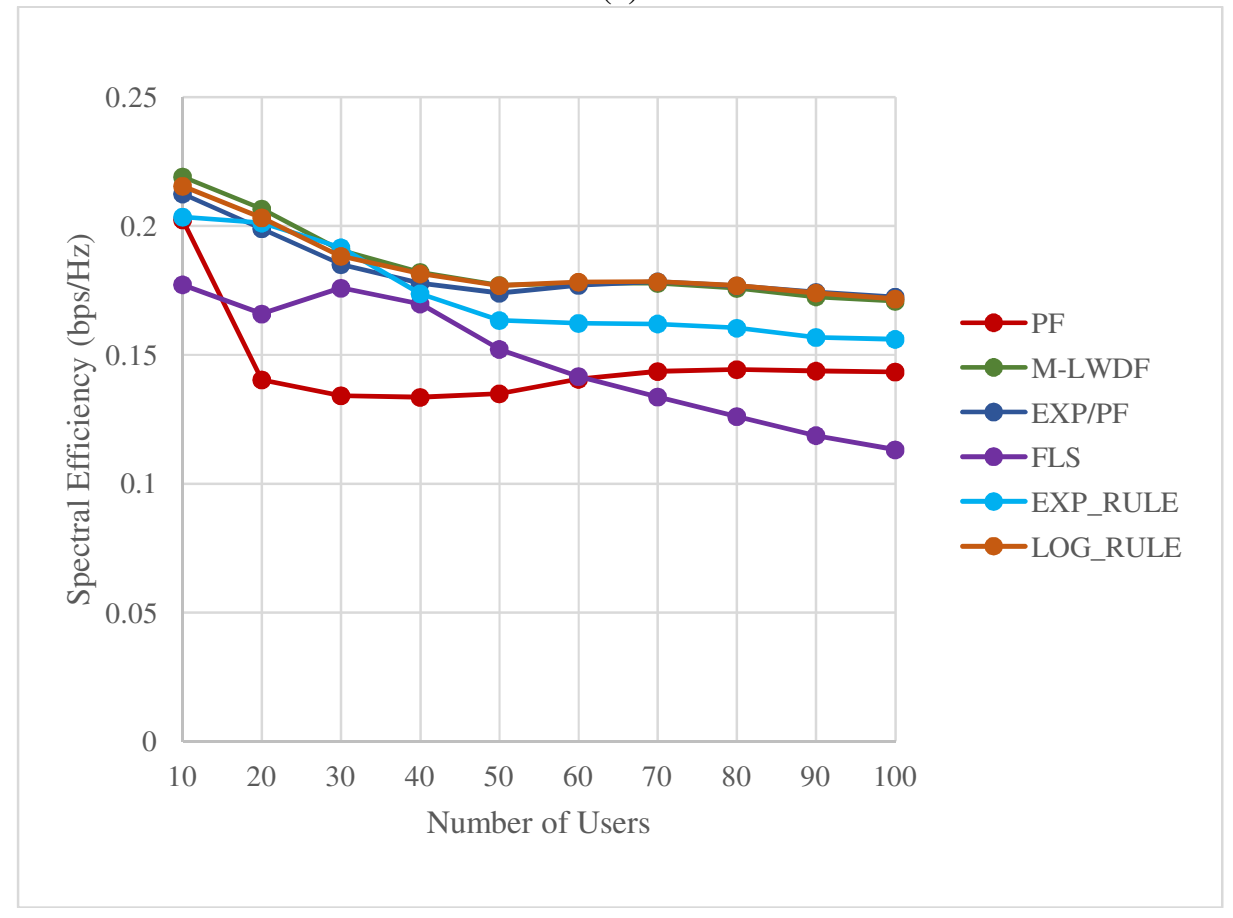

(b) 


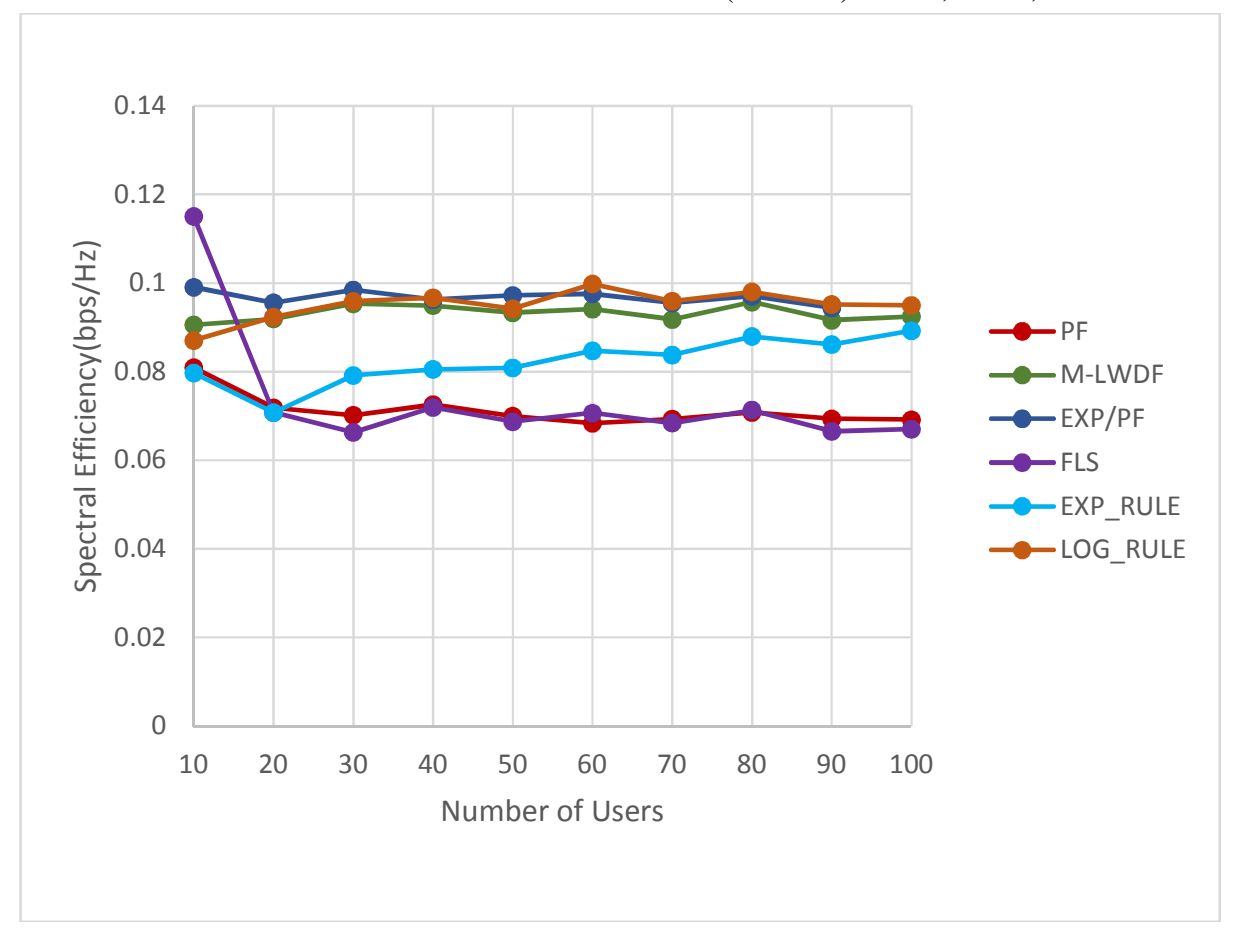

(c)

Figure 10: Cell spectral efficiency for different users' speed (a) $3 \mathrm{~km} / \mathrm{h}$ (b) $30 \mathrm{~km} / \mathrm{h}$ (c) $120 \mathrm{~km} / \mathrm{h}$

\section{CONCLuSion}

In this work, a comparative study on the performances of PF, EXP/PF, EXP Rule, M-LWDF, LOG Rule and FLS packet scheduling algorithms proposed for LTE downlink system has been reported. Performance is evaluated in single cell with interference environment while increasing user number and user speed. Results show that the performances of these six scheduling schemes degrade on average with increasing users' speed. For real-time flow, FLS scheme outperforms other five schemes in terms of packet delay, packet loss ratio, and average throughput, whereas for non-real time flow, FLS scheme shows worst average throughput performance among the six algorithms. For NRT flow, EXP-PF scheme shows better average throughput performance on average. It is also observed that for RT traffic, PF algorithms is not suitable as it shows higher PLR and packet delay, and lower average throughput compared with other schemes. Our future work includes to make a comparative analysis of LTE downlink packet scheduling algorithms with considering multi-cell scenarios.

\section{REFERENCES}

[1] Cox, C. (2012), An Introduction to LTE, LTE-Advanced, SAE and 4G Mobile Communications, Hoboken, N.J.: John Wiley \& Sons Ltd, Chichester.

[2] Hämäläinen, S., Sanneck, H. and Sartori, C. (2012), LTE Self-Organizing Networks: Network Management Automation for Operational Efficiency, Hoboken, N.J.: Wiley.

[3] Ghosh. A. and Ratasuk, R. (2011), Essentials of LTE and LTE-A: Cambridge University Press. 
International Journal of Wireless \& Mobile Networks (IJWMN) Vol. 7, No. 5, October 2015

[4] Capozzi, F., Piro, G., Grieco, L.A., Boggia, G. and Camarda, P. (2013), "Downlink Packet Scheduling in LTE Cellular Networks: Key Design Issues and a Survey," IEEE Communications Surveys \& Tutorials, Second Quarter 2013, Vol. 15(2), pp.678-700.

[5] Dardouri, S., \& Bouallegue, R. (2014), "Comparative study of scheduling algorithms for LTE networks," World Academy of Science, Engineering and Technology, International Journal of Computer, Information Science and Engineering, Vol. 8(3), 445-450.

[6] Holma. H. and Toskala, A. (2009), LTE for UMTS : OFDMA and SC-FDMA based radio access, Chichester, U.K.: Wiley.

[7] Piro, G., Grieco, L. A., Boggia, G., Capozzi, F. and Camarda, P. (2011), "Simulating LTE cellular systems: an open- source framework," IEEE Transactions on Vehicular Technology, vol. 60, pp. 498513.

[8] Afroz, F., Barua, S. and Sandrasegaran, K. (2014), "Performance Analysis of FLS, EXP, LOG and M-LWDF Packet Scheduling Algorithms in Downlink 3GPP LTE System," International Journal of Wireless \& Mobile Networks (IJWMN), Vol. 6(5), PP. 77-91.

[9] Dahlman, E., Parkvall, S., Sköld, J. and Beming, P. (2007), 3G Evolution: HSPA and LTE for Mobile Broadband, Amsterdam; Oxford: Elsevier Academic Press.

[10] Basukala, R., Ramli, H. A. M. and Sandrasegaran, K. (2009), "Performance analysis of EXP/PF and M-LWDF in downlink 3GPP LTE system," 1st AH-ICI on internet, pp. 1-5.

[11] Ramli, H.A.M., Sandrasegaran, K., Basukala, R. and Wu, L. (2009), "Modeling and Simulation of Packet Scheduling in the Downlink Long Term Evolution System," 15th Asia-Pacific Conference on Communications, pp.68-71.

[12] Ramli, H. A. M., Basukala, R., Sandrasegaran, K. and Patachaianand, R. (2009), "Performance of well known packet scheduling algorithms in the downlink 3GPP LTE system," in Communications (MICC), IEEE 9th Malaysia International Conference, pp. 815-820.

[13] Al-Jaradat, H., Sandrasegaran, K. (2013), "On the Performance of PF, MLWDF and EXP/PF algorithms in LTE," International Journal of Computers \& Technology, Vol. 8, No. 1, pp. 698-706.

[14] Jalali, A., Padovani, R. and Pankaj, R. (2000), "Data Throughput CDMAHDR a High EfficiencyHigh Data Rate Personal Communication Wireless System," in IEEE 51st Vehicular Technology Conference Proceedings, Tokyo, pp. 1854-1858.

[15] Choi, J.-G. and Bahk, S. (2007) "Cell-throughput analysis of the proportional fair scheduler in the single-cell environment," IEEE Transactions on Vehicular Technology, vol. 56, no. 2, pp. 766-778.

[16] Biernacki, A., \& Tutschku, K. (2013) "Comparative performance study of LTE downlink schedulers," Wireless Personnel Communication, Vol. 74(2), pp. 585-599.

[17] Al-Manthari, B. and Hassanein, H. (2007), "Packet Scheduling in 3.5G High-Speed Downlink Packet Access Networks: Breadth and Depth,” IEEE Network, Vol.21(1), pp.41-46.

[18] Andrews, M., Kumaran, K., Ramanan, K., Stolyar, A., Whiting, P. and Vijayakumar, R. (2001), "Providing Quality of Service over a Shared Wireless Link," IEEE Communications Magazine, vol. 39, pp. 150-154.

[19] Rhee, J.-H., Holtzman, J. M. and Kim D. K. (2003), "Scheduling of Real/Nonreal Time Services: Adaptive EXP/PF Algorithm," in the 57th IEEE Semiannual Vehicular Technology Conference, vol. 1, pp. 462-466.

[20] Rhee, J.-H.,Holtzman, J. M. and Kim, D. K. (2004), "Performance Analysis of the Adaptive EXP/PF Channel Scheduler in an AMC/TDM System," IEEE Communications Letters, vol. 8, pp. 4978-4980.

[21] Afroz, F., Sandrasegaran, K. and Ghosal, P. (2014), "Performance Analysis of PF, M-LWDF and EXP/PF Packet Scheduling Algorithms in 3GPP LTE Downlink," Australasian Telecommunication Networks and Applications Conference (ATNAC), IEEE, pp. 87-92.

[22] Piro, G., Grieco, L. A., Boggia, G., Fortuna, R. and Camarda, P. (2011), "Two-Level Downlink Scheduling for Real-Time Multimedia Services in LTE Networks”, IEEE Transaction on Multimedia, Vol. 13, No. 5.

[23] Shakkottai. S. and Stolyar, A. (2002) "Scheduling for Multiple Flows Sharing a Time-Varying Channel: The Exponential Rule", in Analytic Methods in Applied Probability, American Mathematical Society Translations, Series 2, A Volume in Memory of F, ed. by Karpelevich (American Mathematical Society, Providence, RI, USA), pp. 185-202.

[24] Sadiq, B., Baek, S. J., \& de Veciana, G. (2011), "Delay-optimal opportunistic scheduling and approximations: The log rule," IEEE/ACM Transactions on Networking, Vol. 19(2), pp. 405-418.

[25] Sadiq, B., Madan, R. and Sampath, A. (2009), "Downlink Scheduling for Multiclass Traffic in LTE," EURASIP Journal on Wireless Communications and Networking, ISSN: 1687-14721. 